\title{
Brain-Permeant and -Impermeant Inhibitors of Fatty Acid Amide Hydrolase Synergize with the Opioid Analgesic Morphine to Suppress Chemotherapy-Induced Neuropathic Nociception Without Enhancing Effects of Morphine on Gastrointestinal Transit
}

\author{
Richard A. Slivicki, Shahin A. Saberi, Vishakh lyer, V. Kiran Vemuri, Alexandros Makriyannis, \\ and Andrea G. Hohmann \\ Program in Neuroscience (R.A.S., V.I., A.G.H.), Department of Psychological and Brain Sciences (R.A.S., S.A.S., V.I., A.G.H.), \\ and Gill Center for Biomolecular Science (A.G.H.), Indiana University, Bloomington, Indiana; and Center for Drug Discovery, \\ Northeastern University, Boston, Massachusetts (V.K.V., A.M.)
}

Received July 26, 2018; accepted September 28, 2018

\begin{abstract}
Opioid-based therapies remain a mainstay for chronic pain management, but unwanted side effects limit therapeutic use. We compared efficacies of brain-permeant and -impermeant inhibitors of fatty acid amide hydrolase (FAAH) in suppressing neuropathic pain induced by the chemotherapeutic agent paclitaxel. Paclitaxel produced mechanical and cold allodynia without altering nestlet shredding or marble burying behaviors. We compared FAAH inhibitors that differ in their ability to penetrate the central nervous system for antiallodynic efficacy, pharmacological specificity, and synergism with the opioid analgesic morphine. (3'-(aminocarbonyl)[1,1'-biphenyl]- 3-yl)-cyclohexylcarbamate (URB597), a brain-permeant FAAH inhibitor, attenuated paclitaxel-induced allodynia via cannabinoid receptor $1\left(\mathrm{CB}_{1}\right)$ and cannabinoid receptor $2\left(\mathrm{CB}_{2}\right)$ mechanisms. URB937, a brainimpermeant $\mathrm{FAAH}$ inhibitor, suppressed paclitaxel-induced allodynia through a $\mathrm{CB}_{1}$ mechanism only. 5-[4-(4-cyano-1butyn-1-yl)phenyl]-1-(2,4-dichlorophenyl)- $N$-(1,1-dioxido-4thiomorpholinyl)-4-methyl-1H-pyrazole-3-carboxamide (AM6545), a peripherally restricted $\mathrm{CB}_{1}$ antagonist, fully reversed the antiallodynic efficacy of $N$-cyclohexyl-carbamic acid,
\end{abstract}

3'-(aminocarbonyl)-6-hydroxy[1,1'- biphenyl]-3-yl ester (URB937) but only partially reversed that of URB597. Thus, URB937 suppressed paclitaxel-induced allodynia through a mechanism that was dependent upon peripheral $\mathrm{CB}_{1}$ receptor activation only. Antiallodynic effects of both FAAH inhibitors were reversed by $N$-(piperidin-1-yl)-5-(4-iodophenyl)-1-(2,4-dichlorophenyl)-4methyl-1H-pyrazole-3-carboxamide (AM251). Antiallodynic effects of URB597, but not URB937, were reversed by 6-iodo-2-methyl-1[2-(4-morpholinyl)ethyl]-1H-indol-3-yl](4-methoxyphenyl)methanone (AM630). Isobolographic analysis revealed synergistic interactions between morphine and either URB597 or URB937 in reducing paclitaxel-induced allodynia. A leftward shift in the dose-response curve of morphine antinociception was observed when morphine was coadministered with either URB597 or URB937, consistent with morphine sparing. However, neither URB937 nor URB597 enhanced morphine-induced deficits in colonic transit. Thus, our findings suggest that FAAH inhibition may represent a therapeutic avenue to reduce the overall amount of opioid needed for treating neuropathic pain with potential to reduce unwanted side effects that accompany opioid administration.

\section{Introduction}

Opioids are recognized as a critical component of the analgesic ladder of the World Health Organization (VargasSchaffer, 2010). However, therapeutic properties are

This work is supported by the National Institutes of Health National Institute on Drug Abuse (NIDA) [Grants DA041229 (A.G.H.) and DA009158 (A.M. and A.G.H.)] and the National Cancer Institute [Grant CA200417 (A.G.H.)], and R.A.S. is supported by T32 NIDA Training Grant DA024628 (R.A.S.) and the 2017 Harlan Scholars Research Program.

https://doi.org/10.1124/jpet.118.252288. accompanied by adverse side effects (e.g., constipation, tolerance, abuse liability, and respiratory depression) (Henry et al., 2015). Prescription opioid abuse (Olsen et al., 2006; Manchikanti et al., 2012) has contributed to opioid overdose deaths that have reached epidemic proportions in the United States (Manchikanti et al., 2012; Paulozzi, 2012). Thus, there is an urgent need to develop alternative therapeutic interventions for chronic pain that are safe, nontoxic, and nonaddictive.

The endocannabinoid system consists of cannabinoid receptors, endocannabinoids (e.g., anandamide and 2-arachidonoyl

ABBREVIATIONS: AM251, $N$-(piperidin-1-yl)-5-(4-iodophenyl)-1-(2,4-dichlorophenyl)-4-methyl-1H-pyrazole-3-carboxamide; AM630, 6-iodo-2methyl-1-[2-(4-morpholinyl)ethyl]-1H-indol-3-yl](4-methoxyphenyl)methanone; AM6545, 5-[4-(4-cyano-1-butyn-1-yl)phenyl]-1-(2,4-dichlorophenyl)- $N$-(1,1-dioxido-4-thiomorpholinyl)-4-methyl-1H-pyrazole-3-carboxamide; $A N O V A$, analysis of variance; $\mathrm{CB}_{1}$, cannabinoid receptor 1 ; $\mathrm{CB}_{2}$, cannabinoid receptor 2; CNS, central nervous system; FAAH, fatty acid amide hydrolase; MGL, monoacylglycerol lipase; URB597, (3'-(aminocarbonyl) [1,1'-biphenyl]- 3-yl)-cyclohexylcarbamate; URB937, N-cyclohexyl-carbamic acid, 3'-(aminocarbonyl)-6-hydroxy[1,1'- biphenyl]-3-yl ester. 
glycerol), and enzymes catalyzing the synthesis and degradation of these endocannabinoids. Activation of cannabinoid receptor $1\left(\mathrm{CB}_{1}\right)$ or cannabinoid receptor $2\left(\mathrm{CB}_{2}\right)$ produces antinociceptive efficacy in preclinical pain models (Rahn and Hohmann, 2009; Woodhams et al., 2017). However, direct $\mathrm{CB}_{1}$ activation also produces tolerance and unwanted side effects (i.e., psychoactivity, withdrawal, motor impairment) (Deng et al., 2015). Inhibitors of endocannabinoid deactivation represent an alternative approach to exploit the therapeutic potential of endocannabinoid signaling while circumventing unwanted side effects. Endocannabinoid tone can be enhanced indirectly through inhibition of enzymes catalyzing endocannabinoid hydrolysis. Fatty acid amide hydrolase (FAAH) is the major enzyme catalyzing degradation of anandamide (Cravatt et al., 1996), whereas monoacylglycerol lipase (MGL) is the major enzyme catalyzing hydrolysis of 2-arachidonoylglycerol (Dinh et al., 2002). Inhibitors of both enzymes suppress nociceptive behaviors in rodent pain models (Kinsey et al., 2010; Schlosburg et al., 2010; Guindon et al., 2013). FAAH inhibitors also lack typical cannabimimetic effects that accompany direct $\mathrm{CB}_{1}$ receptor activation (Kinsey et al., 2010; Soukupová et al., 2010; Guindon et al., 2013; Kwilasz et al., 2014; Sakin et al., 2015). The peripherally-restricted FAAH inhibitor $N$-cyclohexyl-carbamic acid, 3 '-(aminocarbonyl)6-hydroxy[1,1' - biphenyl]-3-yl ester (URB937) displays antinociceptive efficacy similar to central nervous system (CNS)-penetrant FAAH inhibitors in preclinical studies (Clapper et al., 2010; Moreno-Sanz et al., 2011; Sasso et al., 2012, 2015). However, although CNS-penetrant FAAH inhibitors are generally well tolerated (Li et al., 2012; Wagenlehner et al., 2017), they lacked efficacy in clinical trials (Huggins et al., 2012; Bradford et al., 2017; Wagenlehner et al., 2017). Furthermore, genetic deletion of FAAH produced central sensitization in a model of inflammatory pain (Carey et al., 2016), suggesting that sustained FAAH inhibition may be pronociceptive under certain conditions. Consequently, peripheral FAAH inhibition alone could be a sufficient and preferable therapeutic strategy for suppressing pathologic pain clinically compared with global FAAH inhibitors.

Cannabinoid and opioid receptor systems interact (Abrams et al., 2011; Befort, 2015). Cannabinoid agonists enhance efficacy of the opioid analgesic morphine in models of visceral pain (Miller et al., 2012), neuropathic pain (Grenald et al., 2017), arthritis (Cox et al., 2007), and acute tail-flick antinociception (Cichewicz and McCarthy, 2003; Cichewicz, 2004; Tham et al., 2005). Both FAAH and MGL inhibitors enhance morphine's antinociceptive efficacy in a neuropathic pain model without enhancing unwanted side effects on gastric motility (Wilkerson et al., 2016, 2017). Whether synthetic opioids interact beneficially with peripherally restricted FAAH inhibitors in a neuropathic pain state has not been previously reported. The contribution of FAAH inhibition outside the CNS to the antiallodynic efficacy of brain-permeant FAAH inhibitors remains poorly understood, and interactions between opioids and cannabinoids in modulating chemotherapy-induced neuropathic pain have never been evaluated.

Paclitaxel produces robust, long-lasting allodynia in 30\%$40 \%$ of patients (Scripture et al., 2006). Characteristic mechanical and cold hypersensitivities have been observed in the distal extremities in both people (Cata et al., 2006) and rodents (Polomano et al., 2001; Deng et al., 2012; Slivicki et al., 2016; Smith et al., 2017; Toma et al., 2017). We evaluated the impact of paclitaxel on evoked pain sensitivity as well as on nestlet-shredding and marble-burying behaviors, behaviors that may reflect affective states associated with neuropathic pain (Wilkerson et al., 2018). We compared the antiallodynic effects of peripherally restricted (URB937) and centrally penetrating (3'-(aminocarbonyl)[1,1'-biphenyl]- 3 yl)-cyclohexylcarbamate (URB597) inhibitors of FAAH with morphine. URB937 is actively extruded from the CNS by an ATP-binding cassette transporter [ABCG2; see Clapper et al. (2010), Moreno-Sanz et al. (2011)] and is, therefore, operationally defined in this report as brain impermeant. We evaluated contributions of $\mathrm{CB}_{1}$ and $\mathrm{CB}_{2}$ receptors to therapeutic effects of URB597 and URB937 in paclitaxel-treated mice using a peripherally restricted $\mathrm{CB}_{1}$ (5-[4-(4-cyano-1butyn-1-yl)phenyl]-1-(2,4-dichlorophenyl)- $N$-(1,1-dioxido4-thiomorpholinyl)-4-methyl- $1 H$-pyrazole-3-carboxamide (AM6545)) antagonist as well as brain-penetrant $\mathrm{CB}_{1}[N-$ (piperidin-1-yl)-5-(4-iodophenyl)-1-(2,4-dichlorophenyl)-4methyl-1H-pyrazole-3-carboxamide (AM251) (Gatley et al., 1997)] and $\mathrm{CB}_{2}$ [6-iodo-2-methyl-1-[2-(4-morpholinyl)ethyl]-1Hindol-3-yl](4-methoxyphenyl)methanone (AM630) (Hosohata et al., 1997)] antagonists. We compared morphine's antiallodynic efficacy when administered in combination with URB597 or URB937 using isobolographic analysis. Finally, we evaluated the impact of synergistic doses on unwanted side effects of opioids in a colonic motility assay.

\section{Materials and Methods}

Subjects. One hundred sixty-four adult male C57BL/6J mice 3 months of age were purchased from Jackson Laboratory (Bar Harbor, ME). Animals were single housed in a temperaturecontrolled facility with food and water ad libitum and maintained on a 12-hour light-dark cycle (7 AM to 7 PM). All experimental procedures were approved by the Bloomington Institutional Animal Care and Use Committee of Indiana University and followed the guidelines of the International Associated for the Study of Pain (Zimmermann, 1983).

Drugs and Chemicals. Paclitaxel (Tecoland Corporation, Edison, $\mathrm{NJ})$ was dissolved in a 1:1:18 ratio of cremophor EL:ethanol:saline (Slivicki et al., 2016) and administered at a volume of $6.67 \mathrm{ml} / \mathrm{kg}$. URB597, URB937, AM251, AM630 (all from Cayman Chemical Company, Ann Arbor, MI), and morphine sulfate (Sigma-Aldrich, St. Louis, MO) were used. AM6545 was synthesized by the authors [V.K.V. and A.M. (Tam et al., 2010)]. Drugs were dissolved in vehicle consisting of $20 \%$ dimethylsulfoxide, $8 \%$ ethanol, $8 \%$ emulphor, and $64 \%$ saline and administered via intraperitoneal injection in a volume of $5 \mathrm{ml} / \mathrm{kg}$. In combination studies, drugs were injected intraperitoneally in a volume of $2.5 \mathrm{ml} / \mathrm{kg}$.

General Experimental Protocol. Behavioral experiments were conducted by a single experimenter (R.A.S., S.A.S., or V.I.) blinded to the treatment condition. Mice were randomly assigned to experimental conditions.

Assessment of Paw-Withdrawal Thresholds to Mechanical Stimulation. Paw-withdrawal thresholds (in grams) to mechanical stimulation were measured using an electronic von Frey anesthesiometer (Alemo 2390-5; IITC, Woodland Hills, CA) as described previously (Lee et al., 2015; Slivicki et al., 2016). Mice were placed on an elevated metal mesh table where they were habituated under individual, inverted plastic cages for at least 20 minutes prior to testing. Following the cessation of exploratory behaviors, a force was applied to the midplantar region of the hind paw with a semiflexible tip connected to the anesthesiometer. Mechanical stimulation was terminated when the mouse withdrew its paw from the mesh surface. The threshold for paw withdrawal was determined in duplicate in 
each paw; responsiveness in each paw was averaged into a single determination for each animal.

Assessment of Cold Allodynia. Sensitivity to cold stimulation was measured in the same animals used to assess mechanical pawwithdrawal thresholds using the acetone method (Slivicki et al., 2016). Approximately 5-6 $\mu \mathrm{l}$ of acetone was applied to the plantar surface of the hind paw using the open end of a blunt 1-ml syringe for each application. Care was taken by the experimenter to ensure that only the acetone was in contact with the paw and that mechanical stimulation was not applied inadvertently with the hub of the syringe itself. The total time the animal spent attending to the acetonestimulated paw (i.e., elevation, shaking, or licking) was recorded for 1 minute following each acetone application. The duration of time animals spent attending to the acetone-stimulated paw was assessed three times in each paw; responsiveness in each paw was then averaged into a single determination for each animal.

Marble Burying. Methods were adapted from Angoa-Pérez et al. (2013) and Wilkerson et al. (2018). Assessment of marble burying was performed during the maintenance phase of paclitaxel-induced neuropathy, when neuropathic pain was established and stable. In brief, 20 glass marbles (each $1.5 \mathrm{~cm}$ in diameter) were placed on the surface of $5 \mathrm{~cm}$ of bedding in a standard polycarbonate cage $(\sim 27 \times 16 \times 14 \mathrm{~cm})$. Mice were placed in the cage away from the marbles and allowed to behave undisturbed for 30 minutes and were then removed from the test cage. The number of marbles that were buried $50 \%$ or greater was assessed (Kinsey et al., 2011). Illumination in the room at the level of the cage lid of the observation chambers was approximately 110 lux (ranging from 72 to 150 lux). Food and water were not available to mice during testing.

Nestlet Shredding Procedure. Nestlet shredding was evaluated as described previously by Negus et al. (2015) and Angoa-Pérez et al. (2013). In brief, nestlet-shredding testing commenced on day 30 following paclitaxel or cremophor administration in the same animals used to assess marble burying. The typical bedding was removed 48 hours prior to testing, and $5 \times 5 \mathrm{~cm}$ of "nestlet" composed of virgin cotton was placed in the home cage. On the test day, mice were habituated for 10 minutes in the test room. Following habituation, the mouse was temporarily transferred to a transfer cage in the same room so that nestlet material that was present in the cage could be unobtrusively removed, and six $(1.7 \times 2.5 \mathrm{~cm})$ nestlets were added to the home cage. The mouse was reintroduced to the home cage away from the nestlet, and animals were subsequently allowed to explore the chamber undisturbed for 100 minutes. The number of nestlet "zones" (i.e., if nestlet was removed from its initial placement) cleared was quantified. The percentage of nestlet shredded was also weighed and calculated as follows: [(unshredded nestlet pretest - unshredded nestlet posttest)/unshredded nestlet pretest] $\times 100$. Illumination in the room at the level of the cage lid of the observation chambers was approximately 120 lux (ranging from 80 to 165 lux). Food and water were not available to mice during testing.

Paclitaxel-Induced Neuropathic Pain. Paclitaxel (4 mg/kg i.p.) or its cremophor-based vehicle was administered once daily every other day over a 6-day period as described previously (Slivicki et al., 2017). Behavioral testing occurred on days $0,4,7$, and 15 as described previously (Deng et al., 2015; Slivicki et al., 2017). All pharmacological treatments began after day 15 following the initiation of paclitaxel/ cremophor vehicle dosing, when behavioral hypersensitivities are established and considered stable (i.e., neuropathy maintenance).

Dose-Response Curves. Following the establishment of paclitaxelinduced hypersensitivities to mechanical and cold stimulation, URB597 (0.01, 0.1, 0.3, 1, 3, and $10 \mathrm{mg} / \mathrm{kg}$ i.p.), URB937 (0.1, 0.3, 1,3 , and $10 \mathrm{mg} / \mathrm{kg}$ i.p.), and morphine (1,3,5,10, 20, and $30 \mathrm{mg} / \mathrm{kg}$ i.p.) were administered in escalating doses every 2-3 days. Behavioral testing occurred 2 hours post injection of URB597/URB937 and 30 minutes post injection of morphine when effects were expected to be maximal (Slivicki et al., 2017; Lin et al., 2018). The dose-response curve for URB597 was published previously (Slivicki et al., 2017) and is used here with permission. Assessments of dose-response curves for URB597, URB937, and morphine alone and in combination with URB597 and URB937 were all performed by the same experimenter (R.A.S.) under blinded conditions and used an identical protocol. $\mathrm{ED}_{50}$ values were calculated for suppression of both mechanical and cold allodynia induced by paclitaxel.

Evaluation of Pharmacological Specificity. The peripherally restricted $\mathrm{CB}_{1}$ antagonist $\mathrm{AM} 6545\left(10 \mathrm{mg} / \mathrm{kg}\right.$ i.p.), the global $\mathrm{CB}_{1}$ antagonist AM251 (5 mg/kg i.p.), and the $\mathrm{CB}_{2}$ antagonist AM630 ( $5 \mathrm{mg} / \mathrm{kg}$ i.p.) were administered 1.5 hours following intraperitoneal dosing with each FAAH inhibitor to produce reversal of established antiallodynic efficacy. Thus, pharmacological specificity of FAAH inhibitor therapeutic actions was evaluated by delivering antagonists 30 minutes prior to behavioral testing when antiallodynic effects of FAAH inhibitors would be expected to be maximal (i.e., 1.5 hours following URB597 and URB937 injection) (Guindon et al., 2013).

Isobolographic Comparisons. $\mathrm{ED}_{50}$ values for morphine, URB597, and URB937 in suppressing paclitaxel-induced responsiveness to mechanical and cold stimulation were used to identify combination doses to be administered in a 1:1 ratio. Combination doses, based on the $\mathrm{ED}_{50}$ values of URB937 + morphine or URB597 + morphine, were administered in an escalating fashion with 2- to 3-day spacing between doses, and the experimentally observed $\mathrm{ED}_{50}$ value of the combination was calculated and compared with the corresponding theoretical $\mathrm{ED}_{50}$ value. Timing of behavioral testing was consistent with what was used to generate individual compound dose-response curves (i.e., 2 hours post injection of URB597/URB937 and 30 minutes post injection of morphine). Synergistic combination doses derived from individual dose-response curves were as follows: mechanical: URB597 (0.04, 0.09, 0.17, 0.34, $0.68 \mathrm{mg} / \mathrm{kg}$ i.p.), URB937 (0.02, 0.04, $0.08,0.17,0.33 \mathrm{mg} / \mathrm{kg}$ i.p. $)$, morphine $(0.42,0.84,1.67,3.34,6.68 \mathrm{mg} / \mathrm{kg}$ i.p.); cold: URB597 (0.08, 0.15, 0.31, 0.62, $1.23 \mathrm{mg} / \mathrm{kg}$ i.p.), URB937 $(0.05,0.09,0.19,0.37,0.74 \mathrm{mg} / \mathrm{kg}$ i.p. $)$, morphine $(0.78,1.56,3.13,6.25$, $12.5 \mathrm{mg} / \mathrm{kg}$ i.p.).

Colonic Transit. Methods were based on Raffa et al. (1987) with minor modifications. Mice were fasted for 24 hours prior to testing. On the test day, mice were allowed to habituate 30 minutes prior to administration of pharmacological treatments. A glass bead $(\sim 2 \mathrm{~mm}$ in diameter; item number 18000-46; Fine Science Tools, Foster City, CA) was inserted $2 \mathrm{~cm}$ in the rectal colon using a semiflexible rubber filament. Separate groups of mice received morphine $(3.34$ or $10 \mathrm{mg} / \mathrm{kg}$ i.p.), URB597 (0.33 mg/kg i.p.), URB937 (0.17 mg/kg i.p.), URB597 $(0.33 \mathrm{mg} / \mathrm{kg}$ i.p. $)+$ morphine (3.34 mg/kg i.p.), URB937 $(0.17 \mathrm{mg} / \mathrm{kg}$ i.p.) + morphine (3.34 mg/kg i.p.), or vehicle to evaluate the potential of either FAAH inhibitor to alter morphine-induced slowing of colonic motility. This study evaluated $\mathrm{ED}_{50}$ doses identified in our assessments of paclitaxel-induced mechanical allodynia (i.e., the most common modality used to assess paclitaxel-induced neuropathic pain in the field) to limit unnecessary animal use. Timing of pharmacological manipulations was identical to that used in assessments of the impact of the same treatments on paclitaxel-induced neuropathic pain. The time to expel the bead (minutes) was recorded. The weight of fecal boli produced was also assessed over a 6 -hour period beginning at the insertion of the pellet.

Statistical Analysis. Paw-withdrawal thresholds (mechanical) and duration of acetone-evoked behavior (cold) were calculated for each paw and averaged into a single determination for each mouse for each stimulus modality. Paired $t$ tests were used to compare postpaclitaxel thresholds to baseline levels of responding. Two-way analysis of variance (ANOVA) was used to determine the dose response of URB597, URB937, and morphine in suppressing paclitaxel-induced mechanical and cold responsiveness relative to vehicle. One-way ANOVA was used to evaluate effects of pharmacological manipulations on mechanical and cold responsiveness, followed by Tukey's post hoc tests (for comparisons between groups). One-way ANOVA was used to evaluate the impact of antagonist treatments on changes in mechanical paw-withdrawal thresholds and duration of time spent attending to cold stimulation induced by FAAH inhibitors, followed by Tukey's post hoc tests. A priori comparisons were also made using Bonferroni's multiple comparison tests [which use the mean square 
error term from the overall ANOVA (Motulsky, 2013)] and paired $t$ tests, as appropriate. All statistical analyses were performed using GraphPad Prism version 5.02 for Windows (GraphPad Software, San Diego, CA; www.graphpad.com). $P<0.05$ was considered statistically significant.

Isobolographic analysis (Tham et al., 2005; Tallarida, 2006) was performed to determine whether the combination of morphine with either FAAH inhibitor was additive or synergistic. To elucidate possible opioid-sparing effects, we also evaluated the impact of URB937 and URB597 on the dose response of morphine to suppress paclitaxel-induced mechanical and cold allodynia. Dose-response curves were constructed for URB937, URB597, and morphine as described earlier. Raw data [i.e., thresholds (in grams) or duration of response to acetone (seconds)] were converted to percentage baseline responding (i.e., prior to paclitaxel or cremophor vehicle treatment) using the following equation: (experimental value - postpaclitaxel baseline)/(prepaclitaxel baseline - postpaclitaxel baseline). $\mathrm{ED}_{50}$ values were calculated using these values via GraphPad Prism 5.0 using nonlinear regression analysis. For all combinations, the $\mathrm{ED}_{50}$ of morphine was plotted on the $x$-axis, and the $\mathrm{ED}_{50}$ of URB937 or URB597 was plotted on the $y$-axis. A line drawn between the two $\mathrm{ED}_{50}$ values represents the theoretical line of additivity. The 1:1 $\mathrm{ED}_{50}$ combination doses of morphine with either URB937 or URB597 were generated separately for mechanical and cold modalities and applied in an escalating fashion with each compound dose increasing at a 2- to 3-day interval between each ascending dose. The experimental combination $\mathrm{ED}_{50}$ values were generated using the combination dose-response curves and plotted against the theoretical values which were derived based on the individual $\mathrm{ED}_{50}$ values alone as previously described (Slivicki et al., 2017). These values were compared statistically using Student's $t$ test.

\section{Results}

General Experimental Results: Effects of Paclitaxel on Mechanical and Cold Stimulation. Paclitaxel decreased paw-withdrawal thresholds $\left(\mathrm{F}_{1,10}=34.67 ; P<0.001\right)$, paw-withdrawal thresholds changed over time $\left(\mathrm{F}_{3,10}=46.67\right.$; $P<0.001$ ), and the interaction between treatment and time was significant $\left(\mathrm{F}_{3,10}=33.90 ; P<0.001\right)$ (Fig. 1A). Similarly, paclitaxel increased cold responsivity $\left(\mathrm{F}_{1,10}=30.56 ; P<\right.$ $0.001)$, cold responsivity changed over time $\left(\mathrm{F}_{3,10}=69.30\right.$; $P<0.001$ ), and the interaction between treatment and time was significant $\left(\mathrm{F}_{3,10}=54.12 ; P<0.001\right)$ (Fig. 1B). There were no differences between any of the groups in the development of paclitaxel-induced mechanical $\left(\mathrm{F}_{3,19}=0.1687\right.$; $P>0.9)$ or cold $\left(\mathrm{F}_{3,19}=0.04731 ; P>0.9\right)$ responsiveness at any time point (data not shown) prior to pharmacological
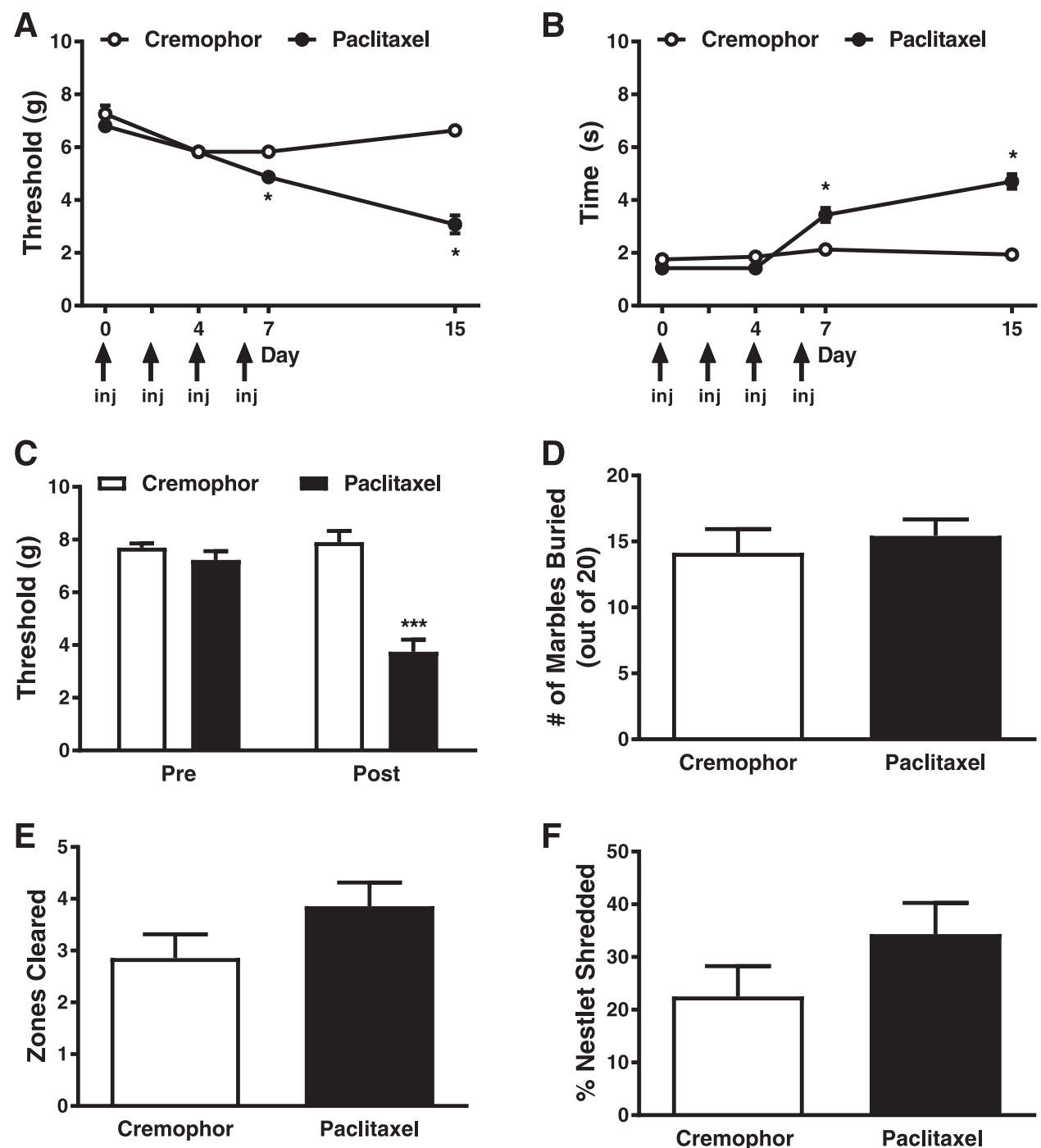

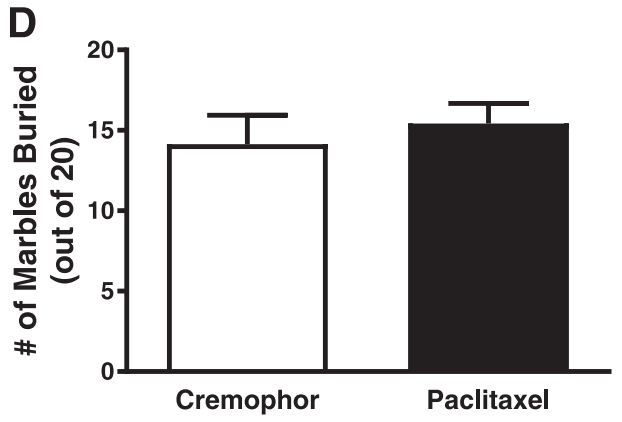

$\mathbf{F}$

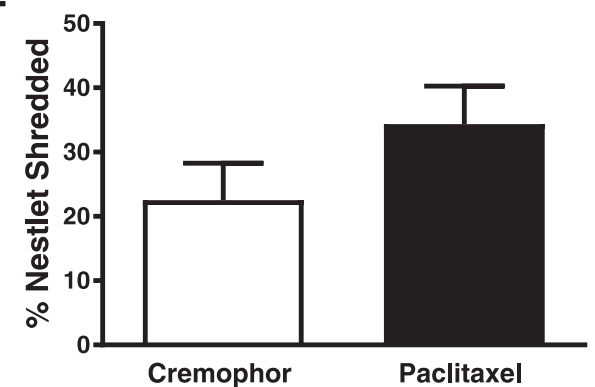

Fig. 1. Paclitaxel treatment produces hypersensitivities to mechanical and cold stimulation without altering marbleburying or nestlet-shredding behaviors. Paclitaxel treatment lowered the threshold for paw withdrawal (grams) to mechanical stimulation (A) and increased the duration of time spent attending to the paw stimulated with cold acetone relative to its cremophor vehicle (B). In a separate cohort of animals, paclitaxel treatment resulted in mechanical hypersensitivity during the maintenance phase of paclitaxel-induced allodynia (C) but did not affect marble burying (D), the number of nestlet zones cleared (E), or the overall percentage of nestlet shredded (F). Data are expressed as the mean \pm S.E.M. $(n=$ 6-7 per group). $* P<0.05$ and $* * * P<$ 0.001 vs. cremophor vehicle two-way ANOVA followed by Bonferroni post hoc test. Arrows denote when paclitaxel or cremophor vehicle was administered. inj, injection. 
A
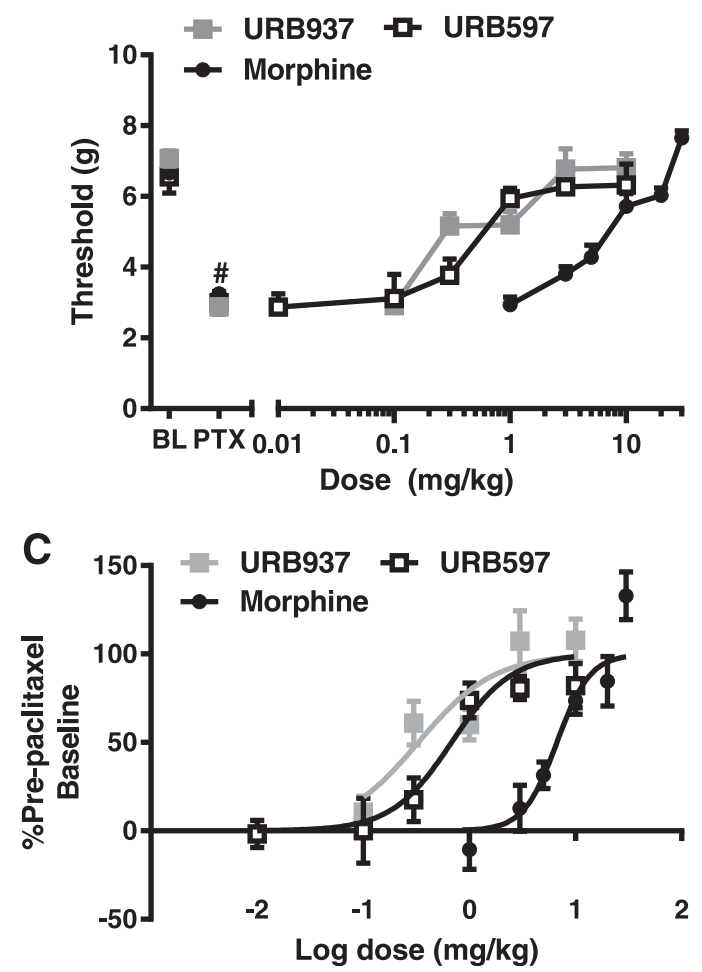

B Cold
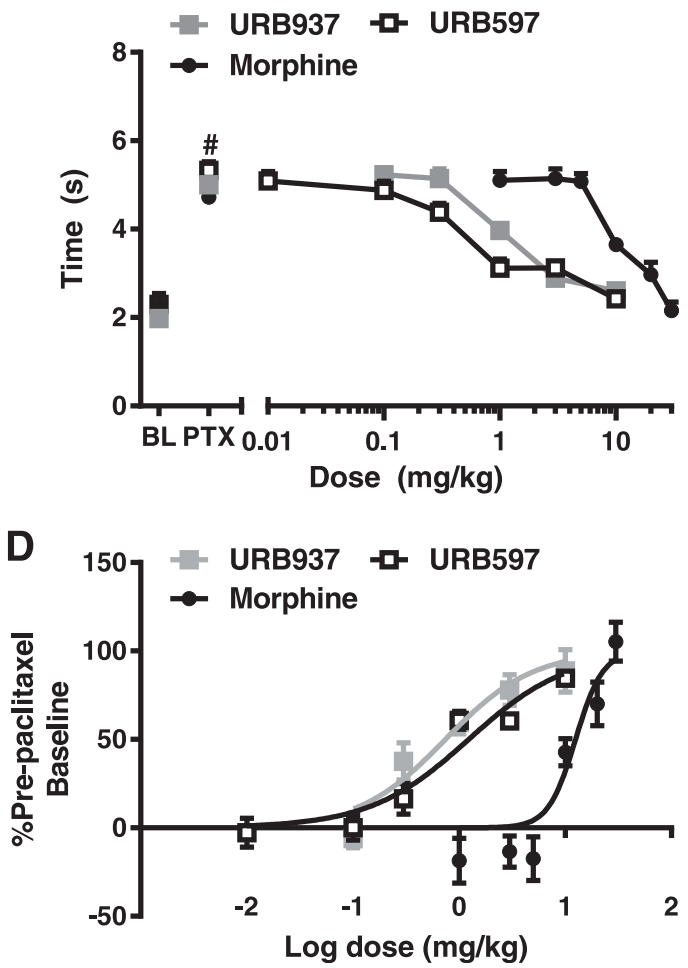

Fig. 2. URB937, URB597, and morphine produce dose-dependent antiallodynic effects in paclitaxel-treated mice. URB597 (0.01, 0.1, 0.3, 1, 3, and $10 \mathrm{mg} / \mathrm{kg}$ i.p.), URB937 (0.1, 0.3, 1,3, and $10 \mathrm{mg} / \mathrm{kg}$ i.p.), and morphine (1, 3, 5, 10, 20, and $30 \mathrm{mg} / \mathrm{kg}$ i.p.) suppressed paclitaxel-induced mechanical (A and C) and cold (B and D) allodynia. Data are expressed as the mean \pm S.E.M. ( $n=5-12$ per group). Figure legend shows the dose administered for each compound [mg/kg i.p. for (A and C) or log mg/kg i.p. for (C and D)]. The URB597 dose-response data were collected by the same experimenter (R.A.S.) and previously published (Slivicki et al., 2017). BL, baseline; PTX, post-paclitaxel.

manipulations. Prior to administration of paclitaxel or its cremophor-based vehicle, the threshold for paw withdrawal and duration of time spent attending to the acetonestimulated paw did not differ between groups in any study $\left[\mathrm{F}_{11,72}=0.8182 ; P>0.62\right.$ for each experiment (mechanical); $\mathrm{F}_{11,72}=1.165 ; P>0.32$ for each experiment (cold) in Figs. 2-5]. Moreover, prior to pharmacological manipulations, paclitaxel lowered the threshold for paw withdrawal to mechanical stimulation and increased the duration of the response to acetone $[P<0.05$ for each experiment (mechanical); $P<0.05$ for each experiment (cold) in Figs. 2-6] in a manner that did not differ between groups $\left[\mathrm{F}_{11,72}=0.6144\right.$; $P>0.81$ for each experiment (mechanical); $\mathrm{F}_{11,72}=0.8 ; P>$ 0.57 for each experiment (cold) in Figs. 2-6].

Paclitaxel Induces Mechanical Hypersensitivity but Does Not Alter Nestlet Shredding or Marble Burying Behaviors. In mice used to assess possible pain-depressed behaviors (i.e., nestlet shredding and/or marble burying), mechanical responses differed between paclitaxel and cremophor vehicle-treated groups $\left(\mathrm{F}_{1,12}=37.73 ; P<0.0001\right)$, mechanical responses were reduced relative to baseline responding (i.e., prior to paclitaxel/cremophor treatment) $\left(\mathrm{F}_{1,12}=21.52 ; P<\right.$ 0.0006), and the interaction between treatment and time was significant $\left(\mathrm{F}_{1,12}=27.42 ; P<0.0002\right)$ (Fig. 1C). Mechanical thresholds were lower in paclitaxel-compared with cremophor vehicle-treated mice prior to the initiation of nestlet-shredding and marble-burying assessments $(P<0.0001$ vs. cremophor $)$ (Fig. 1C).
In the same cohort of animals, paclitaxel did not alter marble burying behavior $(P>0.56)$ (Fig. 1D) or change either the amount of nestlet shredded $(P>0.17)$ (Fig. 1E) or the number of nestlet zones cleared $(P>0.14)($ Fig. $1 F)$ relative to cremophor vehicle-treated animals.

Brain-Permeant and -Impermeant Inhibitors of FAAH Dose-Dependently Reduce Paclitaxel-Induced Hypersensitivities to Mechanical and Cold Stimulation. URB597, URB937, and morphine all dose-dependently reduced mechanical hypersensitivities induced by paclitaxel relative to post-paclitaxel pre-injection responding (Fig. 2, A and $\mathrm{C}$ ) with corresponding $\mathrm{ED}_{50}$ (95\% confidence interval) values of $0.68(0.41-1.14) \mathrm{mg} / \mathrm{kg}$ i.p. for URB597, 0.33 (0.18-0.63) $\mathrm{mg} / \mathrm{kg}$ i.p. for URB937, and 6.68 (4.91-9.11) $\mathrm{mg} / \mathrm{kg}$ i.p. for morphine.

Additionally, URB597, URB937, and morphine dosedependently reduced cold hypersensitivities induced by paclitaxel relative to post-paclitaxel pre-injection responding (Fig. 2, B and D) with $\mathrm{ED}_{50}$ (95\% confidence interval) values of $1.23(0.81-1.87) \mathrm{mg} / \mathrm{kg}$ i.p. for URB597, 0.74 (0.46-1.22) $\mathrm{mg} / \mathrm{kg}$ i.p. for URB937, and 12.5 (9.50-16.45) $\mathrm{mg} / \mathrm{kg}$ i.p. for morphine.

Cannabinoid Receptor Antagonist Treatments Do Not Alter Paclitaxel-Induced Allodynia. None of the antagonist treatments, administered alone in the absence of FAAH inhibitors, altered paclitaxel-induced hypersensitivities to mechanical $\left(\mathrm{F}_{3,22}=2.783 ; P>0.06\right)($ Fig. $3 \mathrm{~A})$ or cold $\left(\mathrm{F}_{3,22}=\right.$ $1.772 ; P>0.18$ ) stimulation (Fig. 3B) relative to vehicle. 
A

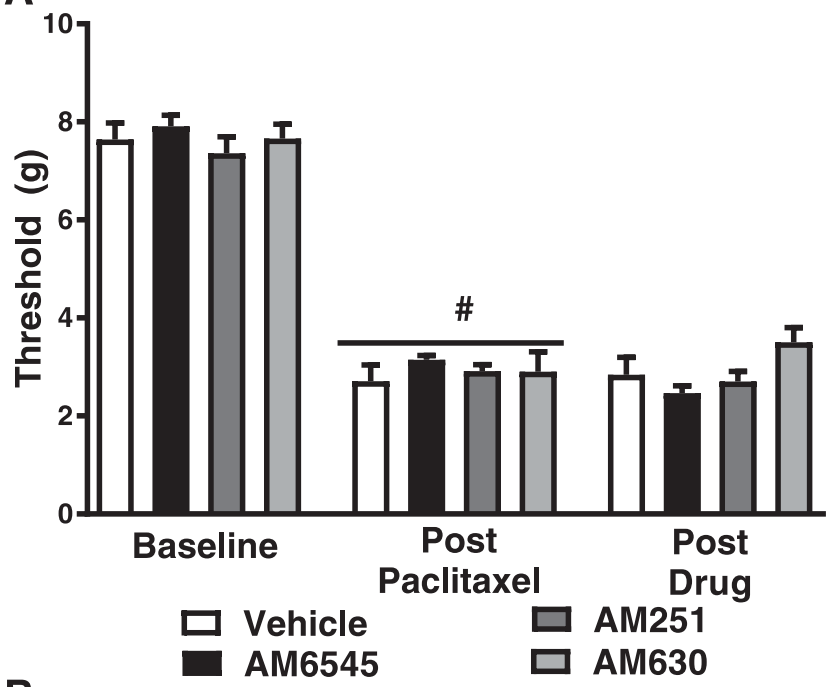

B

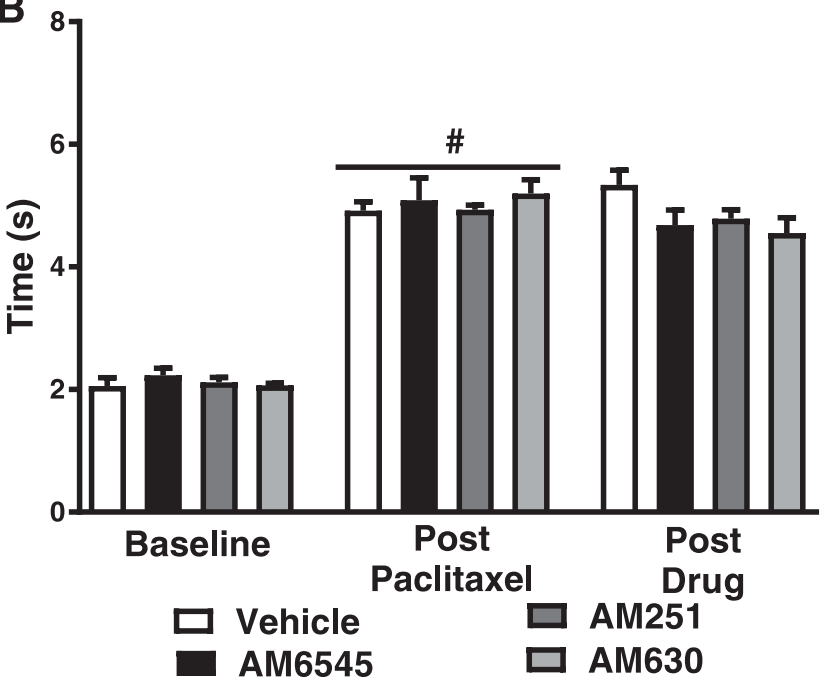

Fig. 3. AM6545, AM251, and AM630 do not alter paclitaxel-induced mechanical or cold allodynia. During the maintenance phase of paclitaxelinduced neuropathic pain, the peripherally restricted $\mathrm{CB}_{1}$ antagonist $\mathrm{AM} 6545$, the $\mathrm{CB}_{1}$ antagonist AM251 (5 mg/kg i.p.), and the $\mathrm{CB}_{2}$ antagonist AM630 do not alter mechanical paw-withdrawal thresholds (A) or the duration of time spent attending to cold acetone (B). Data are expressed as the mean \pm S.E.M. $(n=5-12$ per group $) .{ }^{\#} P<0.05$ vs. prepaclitaxel baseline, one-way ANOVA followed by Tukey's post hoc test.

The Peripherally Restricted $\mathrm{CB}_{1}$ Antagonist AM6545 Fully Reverses Antiallodynic Effects of URB937 but Only Partially Reverses Antiallodynic Effects of URB597. Following paclitaxel treatment, mechanical pawwithdrawal thresholds $\left(\mathrm{F}_{4,36}=19.36 ; P<0.01\right)$ and time spent attending to cold stimulation $\left(\mathrm{F}_{4,36}=20.61 ; P<0.01\right)$ differed between groups receiving FAAH inhibitors in either the presence or absence of AM6545 (Fig. 4). Both URB597 $(1 \mathrm{mg} / \mathrm{kg}$ i.p.) and URB937 ( $1 \mathrm{mg} / \mathrm{kg}$ i.p.) increased pawwithdrawal thresholds in paclitaxel-treated mice relative to vehicle ( $P<0.001$ vs. vehicle for each comparison) (Fig. 4A). AM6545 $(10 \mathrm{mg} / \mathrm{kg}$ i.p.) fully reversed the antiallodynic actions of URB937 $(P<0.001$ vs. URB937, $P>0.05$ vs. vehicle) (Fig. 4A) but only partially reversed the antiallodynic actions of URB597 in attenuating paclitaxel-induced
A

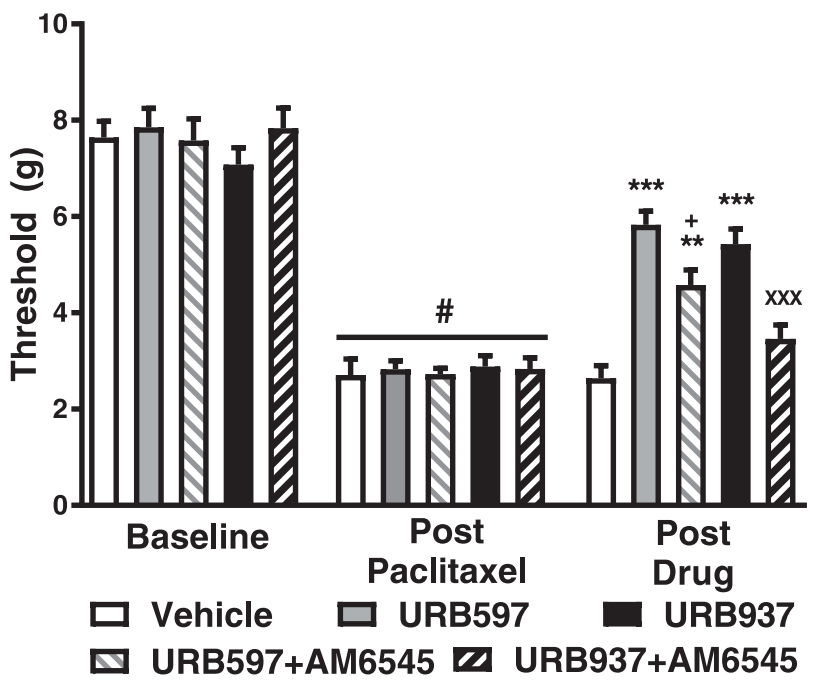

B

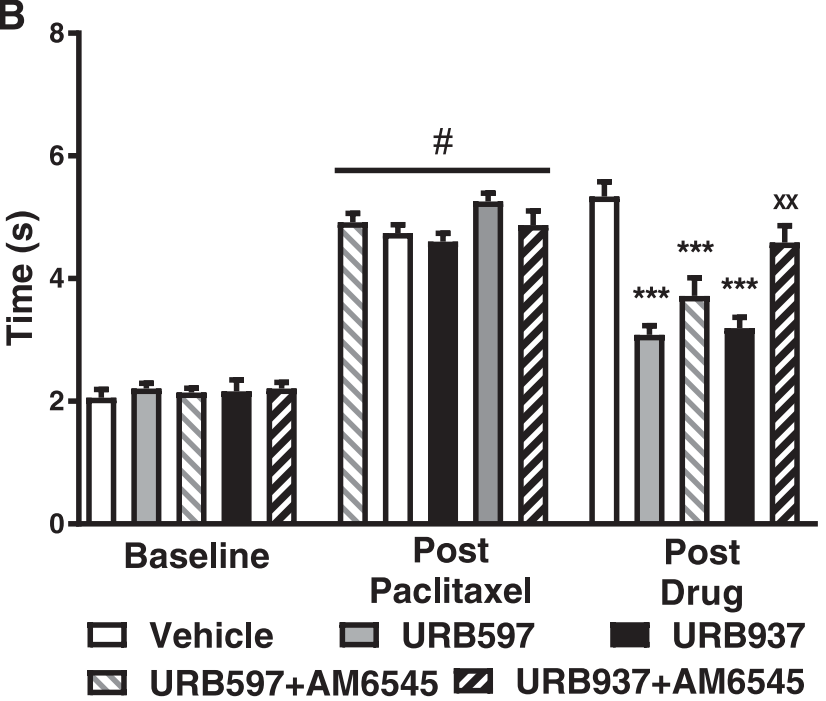

Fig. 4. The peripherally restricted $\mathrm{CB}_{1}$ antagonist $\mathrm{AM} 6545$ fully reverses antiallodynic effects of URB937 and partially reverses antiallodynic effects of URB597. (A) AM6545 $(10 \mathrm{mg} / \mathrm{kg}$ i.p. $)$ fully reversed the efficacy of URB937 (1 mg/kg i.p.) in reducing paclitaxel-induced hypersensitivity to mechanical stimulation but only partially reversed the antiallodynic efficacy of URB597. (B) Paclitaxel-induced hypersensitivity to cold stimulation was attenuated by both URB597 and URB937. AM6545 reversed the efficacy of URB937 but not URB597 in reducing paclitaxel-induced hypersensitivity to cold stimulation. Data are expressed as the mean \pm

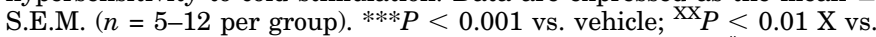
URB937, one-way ANOVA followed by Tukey's post hoc test; ${ }^{\#} P<0.05$ vs. prepaclitaxel baseline, paired two-tailed $t$ test.

mechanical responsiveness $(P<0.05$ vs. URB597, $P<0.01$ vs. vehicle; Fig. 4A)

In paclitaxel-treated mice, both URB597 (1 mg/kg i.p.) and URB937 ( $1 \mathrm{mg} / \mathrm{kg}$ i.p.) decreased cold response times relative to vehicle $(P<0.001 \mathrm{vs}$. vehicle for each comparison) (Fig. 4B). AM6545 (10 mg/kg i.p.) did not reverse URB597-mediated attenuations in paclitaxel-induced cold response times $(P>$ 0.05 vs. URB597, $P<0.001$ vs. vehicle) but fully reversed URB937's effect on cold responsiveness $(P<0.01$ vs. URB937, $P>0.05$ vs. vehicle) (Fig. 4B). 

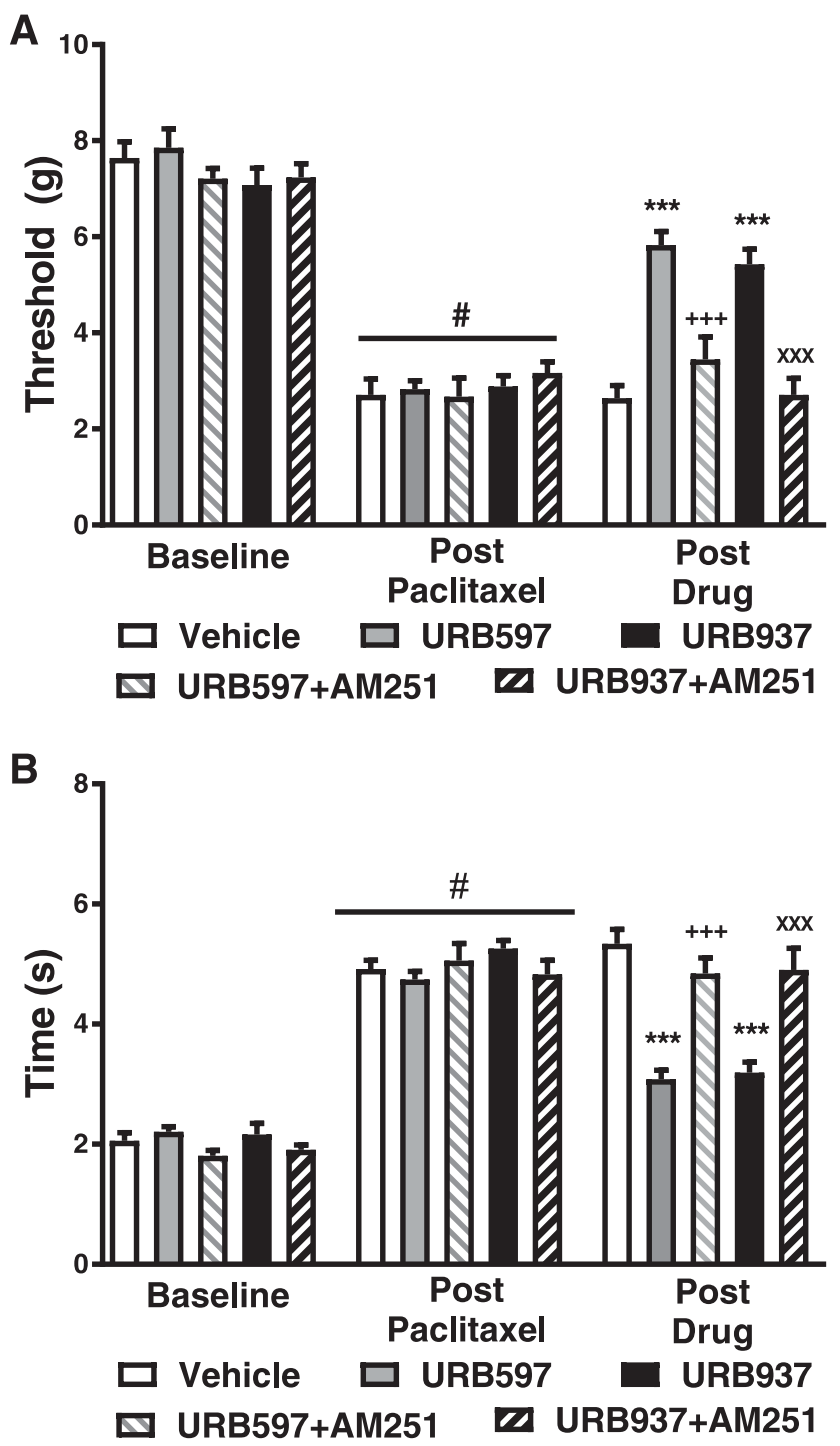

Fig. 5. The $\mathrm{CB}_{1}$ antagonist $\mathrm{AM} 251$ reverses antiallodynic efficacy of both URB937 and URB597. The $\mathrm{CB}_{1}$ antagonist AM251 (5 mg/kg i.p.) reversed the efficacy of URB937 ( $1 \mathrm{mg} / \mathrm{kg}$ i.p. $)$ and URB597 $(1 \mathrm{mg} / \mathrm{kg}$ i.p. $)$ in reducing paclitaxel-induced hypersensitivity to mechanical stimulation (A) and cold stimulation (B). Data are expressed as the mean $\mathrm{ED}_{50} \pm$ S.E.M. ( $n=6-12$ per group). ${ }^{* * *} P<0.001$ vs. vehicle; ${ }^{++} P<0.001$ vs. URB597; $\mathrm{xxx}_{P}<0.001$ vs. URB937, one-way ANOVA followed by Tukey's post hoc test; ${ }^{\#} P<0.05$ vs. prepaclitaxel baseline, paired two-tailed $t$ test.

The $\mathrm{CB}_{1}$ Antagonist AM251 Reverses the Antiallodynic Effects of Both URB937 and URB597. In paclitaxel-treated mice, mechanical paw-withdrawal thresholds $\left(\mathrm{F}_{4,36}=21.07 ; P<0.01\right)$ and time spent attending to cold stimulation $\left(\mathrm{F}_{4,36}=21.27 ; P<0.01\right)$ differed between groups receiving FAAH inhibitors in the presence and absence of the $\mathrm{CB}_{1}$ antagonist AM251 (Fig. 5). Both URB597 $(1 \mathrm{mg} / \mathrm{kg}$ i.p.) and URB937 (1 mg/kg i.p.) increased mechanical pawwithdrawal thresholds relative to vehicle $(P<0.001 \mathrm{vs}$. vehicle for each comparison) (Fig. 5A). AM251 (5 mg/kg i.p.) fully reversed the attenuation of paclitaxel-induced mechanical allodynia produced by URB597 $(P<0.001$ vs. URB597, $P>$ 0.05 vs. vehicle) and URB937 $(P<0.001$ vs. URB937, $P>0.05$ vs. vehicle) (Fig. 5A).
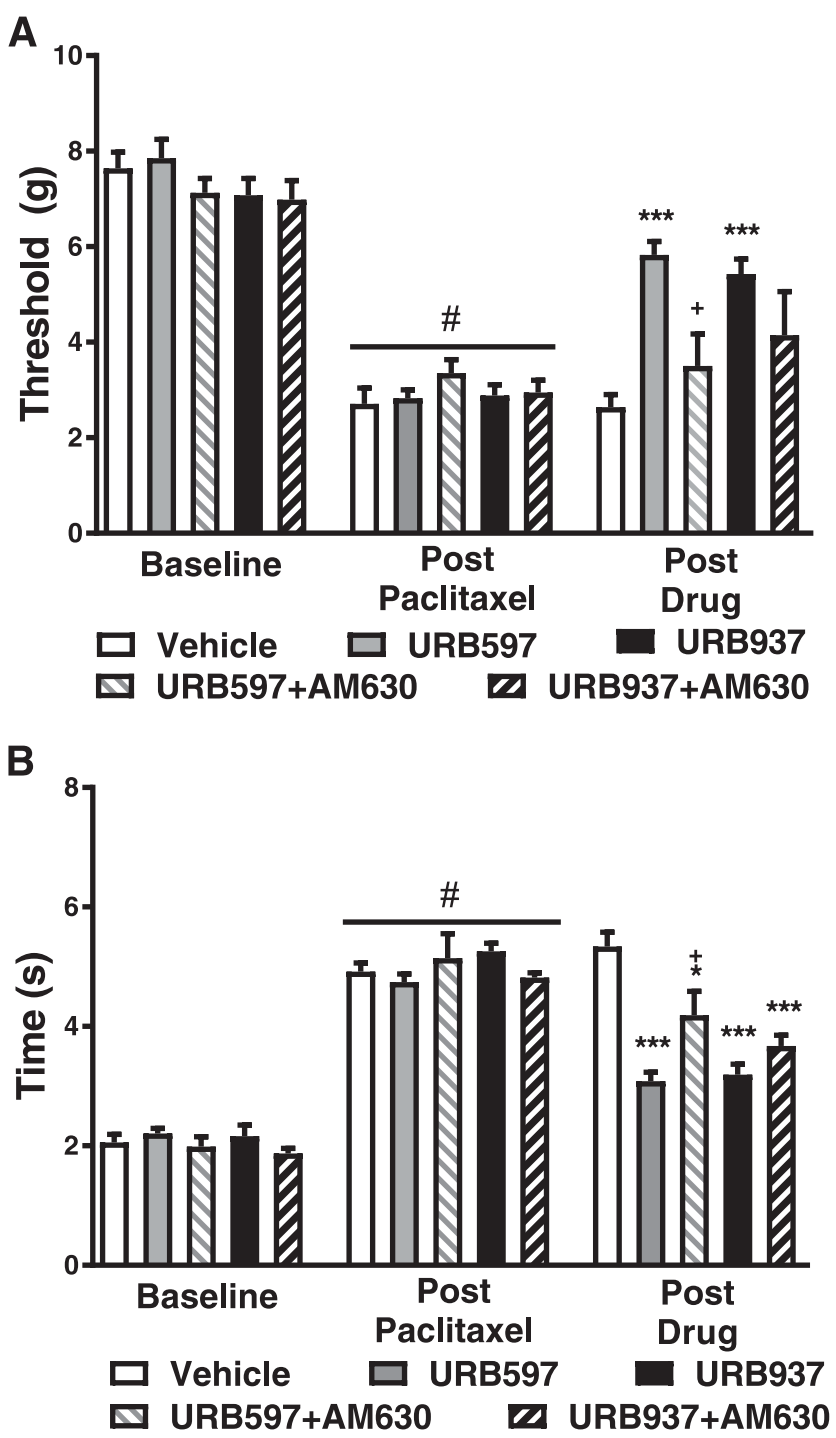

Fig. 6. The $\mathrm{CB}_{2}$ antagonist $\mathrm{AM} 630$ reverses the antiallodynic efficacy of URB597 but not URB937. The $\mathrm{CB}_{2}$ antagonist AM630 $(5 \mathrm{mg} / \mathrm{kg}$ i.p.) reversed the efficacy of URB597 (1 mg/kg i.p.) but not URB937 $(1 \mathrm{mg} / \mathrm{kg}$ i.p.) in reducing paclitaxel-induced hypersensitivity to mechanical (A) and cold (B) stimulation. Data are expressed as the mean $\mathrm{ED}_{50} \pm$ S.E.M. $(n=$ $6-12$ per group). ${ }^{* * *} P<0.001$ vs. vehicle; ${ }^{+} P<0.05$ vs. URB597, one-way ANOVA followed by Tukey's post hoc test; ${ }^{\#} P<0.05$ vs. prepaclitaxel baseline, paired two-tailed $t$ test.

Both URB597 (1 mg/kg i.p.) and URB937 (1 mg/kg i.p.) decreased paclitaxel-induced cold response times relative to vehicle $(P<0.001$ vs. vehicle for each comparison) (Fig. 5B). AM251 (5 mg/kg i.p.) reversed attenuations in paclitaxelinduced cold response times induced by either URB597 $(P<$ 0.001 vs. URB597, $P>0.05$ vs. vehicle) or URB937 $(P<0.01$ vs. URB937, $P>0.05$ vs. vehicle) (Fig. 5B).

The $\mathrm{CB}_{2}$ Antagonist AM630 Reverses the Antiallodynic Effects of URB597 but Not URB937. In paclitaxel-treated mice, mechanical paw-withdrawal thresholds $\left(\mathrm{F}_{4,36}=7.145 ; P<\right.$ $0.01)$ and duration of responses to cold stimulation $\left(\mathrm{F}_{4,36}=18.76\right.$; $P<0.01$ ) were altered in groups receiving FAAH inhibitors in the presence and absence of the $\mathrm{CB}_{2}$ antagonist AM630. Both URB597 (1 mg/kg i.p.) and URB937 ( $1 \mathrm{mg} / \mathrm{kg}$ i.p.) increased mechanical paw-withdrawal thresholds relative to vehicle 
A
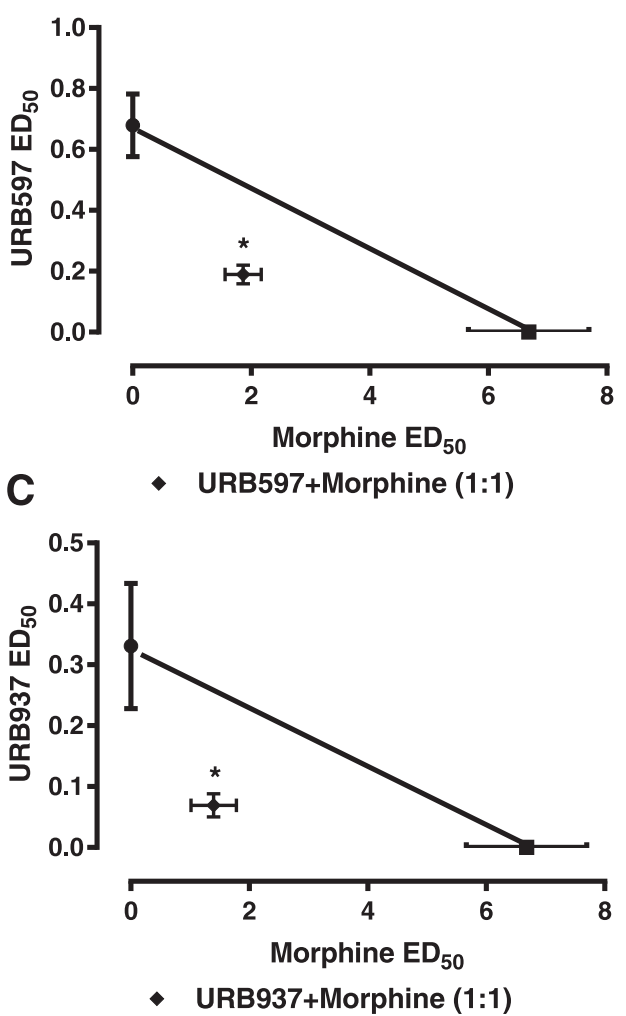

B Cold
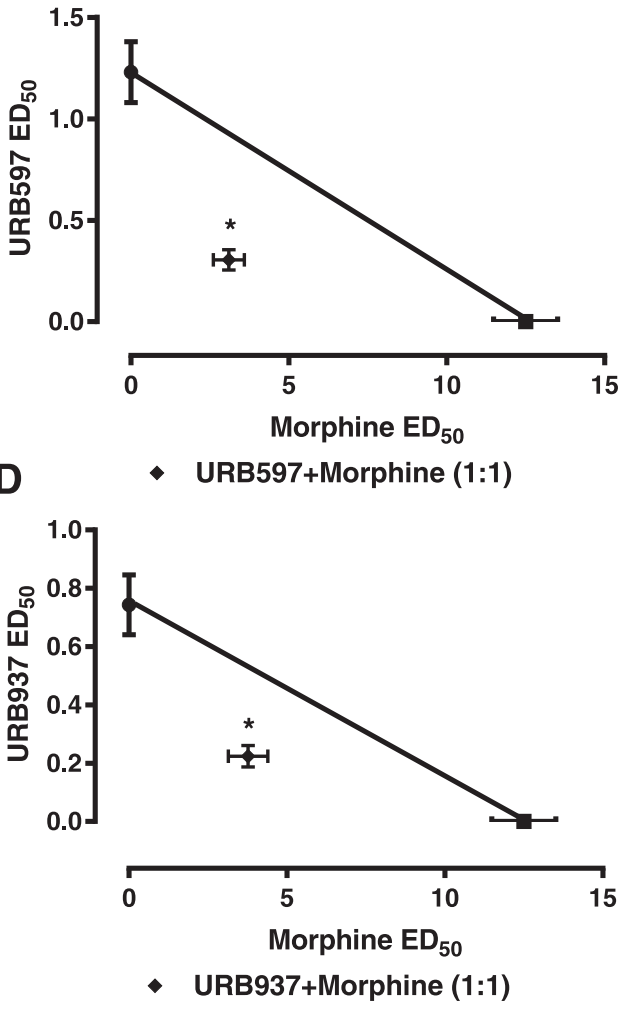

Fig. 7. The brain-permeant FAAH inhibitor URB597 synergizes with morphine in reducing paclitaxel-induced allodynia. Morphine synergized with the centrally penetrating FAAH inhibitor URB597 in suppressing both mechanical (A) and cold (B) hypersensitivities as demonstrated by the observed $\mathrm{ED}_{50}$ of each combination being significantly less than the theoretical $\mathrm{ED}_{50}$. Morphine produced synergistic antinociceptive effects with the peripherally restricted FAAH inhibitor URB937 in suppressing paclitaxel-induced mechanical allodynia (C) and cold allodynia (D) as demonstrated by the observed $\mathrm{ED}_{50}$ of each combination being significantly less than the theoretical $\mathrm{ED}_{50}$. Data are expressed as the mean $\mathrm{ED}_{50} \pm$ S.E.M. ( $n=6$ per group). $* P<0.05$ vs. theoretical additive values, two-tailed $t$ test using Welch's correction.
( $P<0.01$ vs. vehicle for each comparison) (Fig. 6A). AM630 (5 $\mathrm{mg} / \mathrm{kg}$ i.p.) reversed the elevation of mechanical pawwithdrawal thresholds induced by URB597 $(P<0.05$ vs. URB597, $P>0.05$ vs. vehicle) but did not reliably reverse the actions of URB937 ( $P>0.05$ vs. URB937, $P>0.05$ vs. vehicle) (Fig. 6A).

Both URB597 (1 mg/kg i.p.) and URB937 (1 mg/kg i.p.) decreased cold response times relative to vehicle $(P<0.001$ vs. vehicle for each comparison) in paclitaxel-treated mice (Fig. 6B). AM630 (5 mg/kg i.p.) partially reversed the attenuation of paclitaxel-induced cold response times induced by URB597 ( $P<0.05$ vs. URB597, $P<0.05$ vs. vehicle) but had no effect on the antiallodynic effects of URB937 $(P>0.05$ vs. URB937, $P<0.001$ vs. vehicle) (Fig. $6 \mathrm{~B}$ ).

Morphine Synergizes with Brain-Permeant and Brain-Impermanent Inhibitors of FAAH. The combination of URB597 + morphine suppressed paclitaxel-induced mechanical allodynia with an observed $\mathrm{ED}_{50}$ of 2.05 (1.47-2.91) $\mathrm{mg} / \mathrm{kg}$ i.p. $(P<0.05$ vs. additive values, two-tailed $t$ test), which was lower than the theoretical additive value of the same combination $\left[\mathrm{ED}_{50}(95 \%\right.$ confidence interval) of URB597 + morphine: 3.68 (2.92-4.44) mg/kg i.p. (Fig. 7A; Table 1)]. Similarly, the combination of URB597 + morphine suppressed paclitaxel-induced cold allodynia with an observed $\mathrm{ED}_{50}$ [3.41 (2.43-4.77) $\mathrm{mg} / \mathrm{kg}$ i.p.] that was lower that the theoretical additive value [6.87 (5.62-8.12) $\mathrm{mg} / \mathrm{kg}$ i.p.] of the same combination $(P<0.05$ two-tailed $t$ test relative to additive values), consistent with antinociceptive synergism (Fig. 7B).

Similarly, the combination of URB937 + morphine suppressed paclitaxel-induced mechanical allodynia with an observed $\mathrm{ED}_{50}$ of $1.47(0.81-2.68) \mathrm{mg} / \mathrm{kg}$ i.p. $(P<0.05$ vs. additive values, two-tailed $t$ test) that was lower than the theoretical additive value of the same combination $\left[\mathrm{ED}_{50}(95 \%\right.$ confidence intervals) of URB937 + morphine: 3.51 (2.75-4.27) mg/kg i.p. (Fig. 7C; Table 1)]. The combination of URB937 + morphine also suppressed cold allodynia with an observed $\mathrm{ED}_{50}[3.99(2.86-5.85) \mathrm{mg} / \mathrm{kg}]$ that was lower that the theoretical additive value [6.62 (5.43-7.81) $\mathrm{mg} / \mathrm{kg}$ i.p.] of the same combination $(P<0.05$, two-tailed $t$ test relative to additive values), consistent with antinociceptive synergism (Fig. 7D).

URB597 and URB937 Produce a Leftward Shift in the Morphine Dose-Response Curve for Suppressing Paclitaxel-Induced Allodynia. The 1:1 ratio of morphine + URB597 shifted the overall $\mathrm{ED}_{50}$ of morphine 3.6-fold [i.e., from 6.68 (4.90-9.11) to 1.86 (1.33-2.60) $\mathrm{mg} / \mathrm{kg}$ i.p.] (Fig. 8A;

\section{TABLE 1}

Isobolographic analysis reveals that antiallodynic effects of morphine synergize with both brain-permeant and -impermeant inhibitors of FAAH to suppress paclitaxel-induced neuropathic pain

Values are the mean theoretical and experimentally observed $\mathrm{ED}_{50}$ (with $95 \%$ confidence intervals) (mg/kg i.p.) for suppression of paclitaxel-induced allodynia.

\begin{tabular}{lcc}
\hline \multirow{2}{*}{ Modality } & \multicolumn{2}{c}{ Combination with Morphine } \\
\cline { 2 - 3 } & Theoretical & Experimental \\
\hline URB597 & & \\
Mechanical & $3.68(2.92-4.44)$ & $2.053(1.47-2.91)^{*}$ \\
Cold & $6.87(5.62-8.12)$ & $3.41(2.43-4.77)^{*}$ \\
URB937 & & \\
Mechanical & $3.51(2.75-4.27)$ & $1.47(0.81-2.68)^{*}$ \\
Cold & $6.62(5.43-7.81)$ & $3.99(2.86-5.85)^{*}$ \\
\hline
\end{tabular}

$* P<0.05$ vs. theoretical $\mathrm{ED}_{50}$ 
A
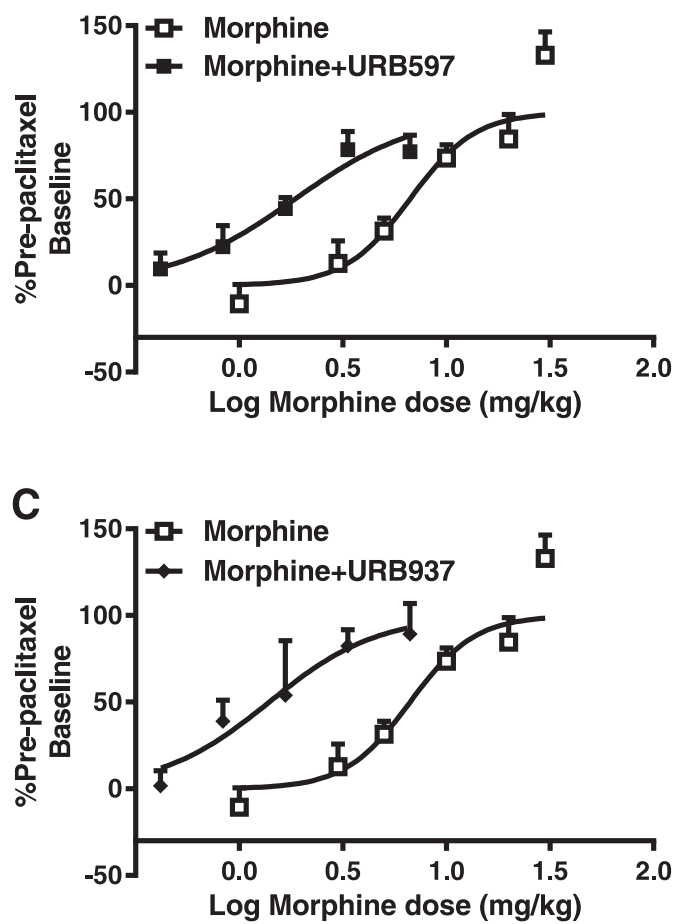

B

\section{Cold}
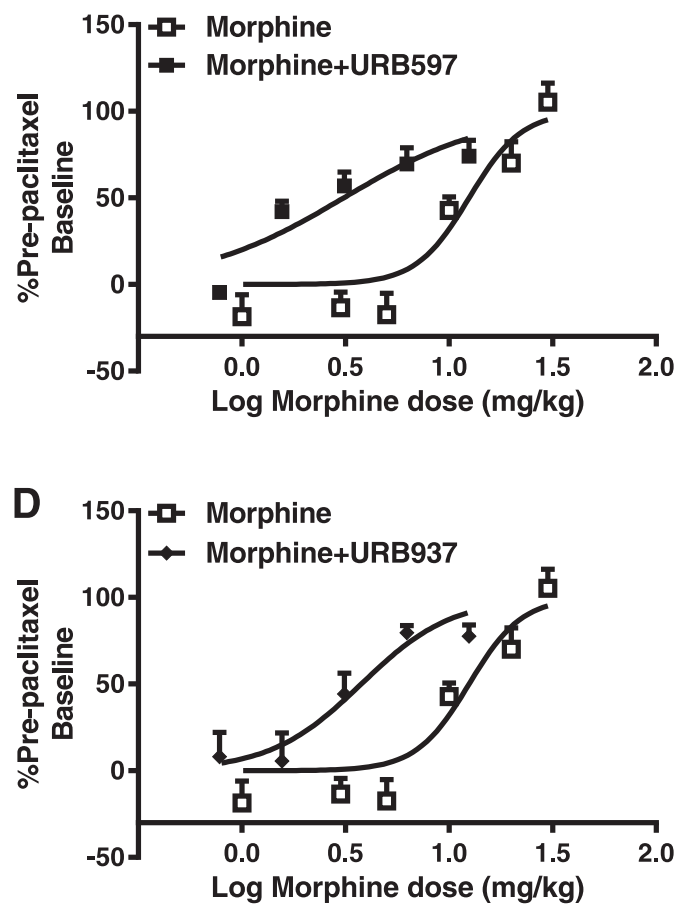

Fig. 8. Both brain-permeant and -impermeant FAAH inhibitors produce a leftward shift in the dose-response curve for morphine antinociception in suppressing paclitaxel-induced neuropathic pain. When coadministered in a 1:1 ratio based on $\mathrm{ED}_{50}$ values, URB597 shifted the dose response of morphine leftward for suppressing paclitaxel-induced hypersensitivities to both mechanical (A) and cold (B) stimulation. When coadministered in a 1:1 ratio based on $\mathrm{ED}_{50}$ values, URB937 also shifted the dose-response curve of morphine leftward for suppressing hypersensitivities to both mechanical (C) and cold (D) stimulation. Data are expressed as the mean $\mathrm{ED}_{50} \pm$ S.E.M. ( $n=6$ per group).

Table 2), whereas the morphine + URB937 combination shifted the $\mathrm{ED}_{50}$ of morphine 4.8-fold [i.e., from 6.68 $(0.49-9.11)$ to $1.398(0.80-2.45) \mathrm{mg} / \mathrm{kg}$ i.p.] (Fig. 8C; Table 2) in reducing paclitaxel-induced mechanical allodynia. Similarly, the morphine + URB597 combination lowered the $\mathrm{ED}_{50}$ of morphine 4-fold [i.e., from $12.5(9.50-16.50)$ to 3.10 (2.21-4.49) $\mathrm{mg} / \mathrm{kg}$ i.p.] (Fig. 8B; Table 2), whereas the morphine + URB937 combination shifted the morphine $\mathrm{ED}_{50}$ 3.3-fold [i.e., from 12.5 (9.50-16.50) to 3.77 (2.70-5.52) $\mathrm{mg} / \mathrm{kg}$ i.p.] in suppressing paclitaxel-induced cold allodynia (Fig. 8D; Table 2).

Combination Treatment with URB597 or URB937 Does Not Alter the Impact of Morphine on Colonic Motility or Fecal Boli Production. Pharmacological treatments altered colonic motility time $\left(\mathrm{F}_{6.37}=20.34 ; P<0.0001\right)$. The high dose of morphine $(10 \mathrm{mg} / \mathrm{kg}$ i.p.) increased overall colonic motility time $(P<0.01$ vs. all groups $)$. By contrast, neither URB597 (0.33 mg/kg i.p.) nor URB937 (0.17 mg/kg i.p.) impaired colonic motility relative to vehicle $(P>0.05)$. The synergistic dose of morphine $(3.34 \mathrm{mg} / \mathrm{kg}$ i.p. $)(P<0.08 \mathrm{vs}$. vehicle; two-tailed $t$ test) trended to increase overall colonic motility time relative to vehicle. Neither combination of URB597 + morphine $(P>0.05)$ nor URB937 + morphine $(P>0.05)$ impaired colonic motility relative to the synergistic dose of morphine alone (Fig. 9).

A one-way ANOVA failed to reveal group differences in the weight of fecal boli produced $\left(\mathrm{F}_{6,37}=1.637 ; P=0.1715\right)$. Nonetheless, Bonferroni's multiple comparison test [which uses the mean square error term from the overall ANOVA (Motulsky, 2013)] revealed that the high dose of morphine $(10 \mathrm{mg} / \mathrm{kg}$ i.p. $)$ decreased the number of fecal boli produced $(P=0.0329 \mathrm{vs}$. vehicle). Neither URB597 (0.33 mg/kg i.p.) nor URB937

TABLE 2

URB597 and URB937 lower the $\mathrm{ED}_{50}$ of morphine in reducing paclitaxel-induced allodynia

Values are the mean of morphine alone and the combination of morphine with either URB597 or URB937 $\mathrm{ED}_{50}$ (with $95 \%$ confidence intervals) (mg/kg i.p.) for suppression of paclitaxel-induced allodynia.

\begin{tabular}{clcc}
\hline \multicolumn{1}{c}{ Modality } & Morphine Alone & Morphine with FAAH Inhibitor & Fold Shift \\
\hline Combination with URB597 & & & \\
Mechanical & $6.68(4.90-9.11)$ & $1.86(1.33-2.60)$ & 3.6 \\
Cold & $12.5(9.50-16.50)$ & $3.10(2.21-4.49)$ & 4 \\
Combination with URB937 & & & \\
Mechanical & $6.68(4.90-9.11)$ & $1.398(0.80-2.45)$ & 4.8 \\
Cold & $12.5(9.50-16.50)$ & $3.77(2.70-5.52)$ & 3.3 \\
\hline
\end{tabular}



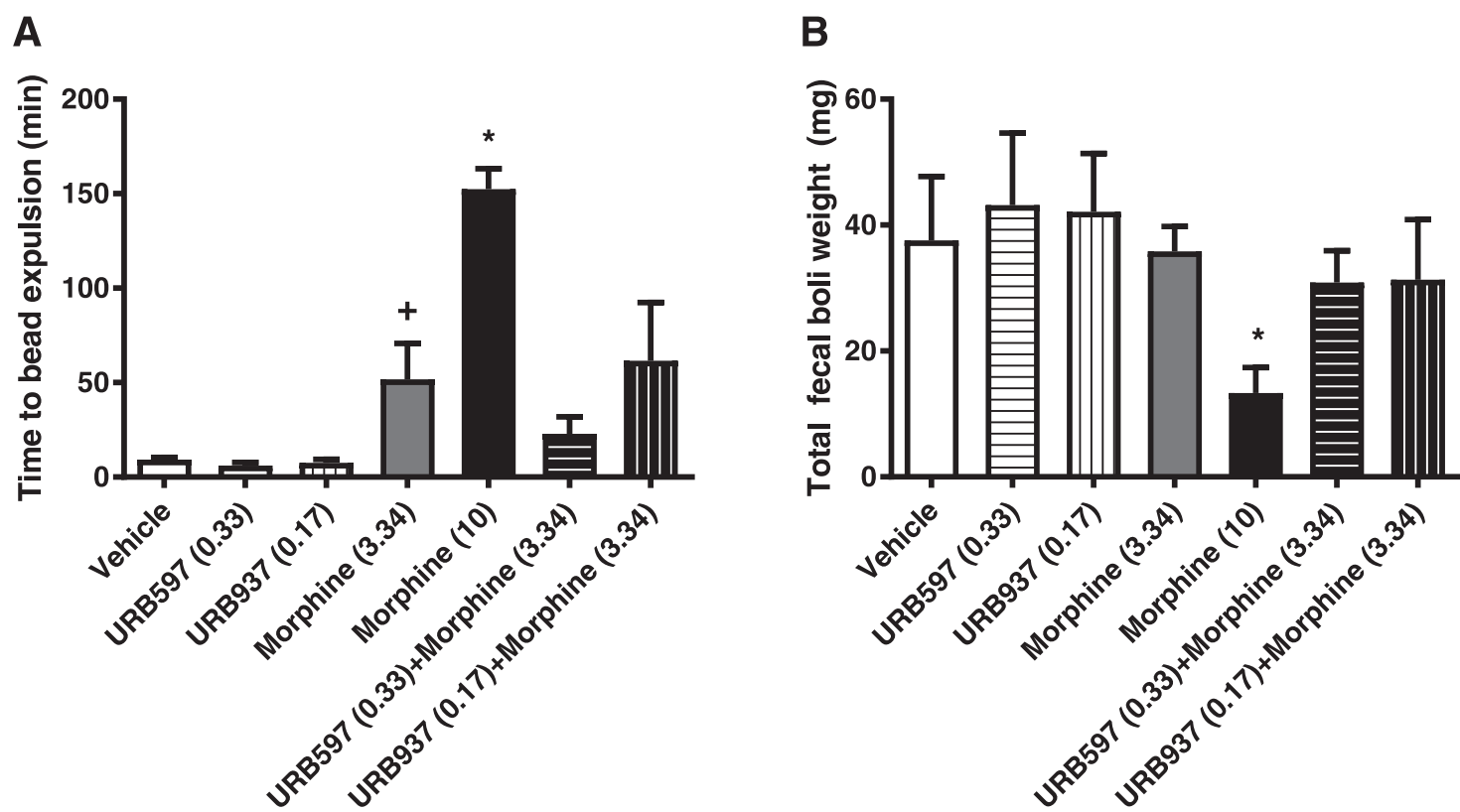

Fig. 9. Brain-permeant and impermeant FAAH inhibitors do not alter colonic transit time or fecal boli output either alone or in combination with morphine. Morphine alone (10 mg/kg i.p. and $3.34 \mathrm{mg} / \mathrm{kg}$ i.p.) increased the amount of time to expel the glass bead. (A) Neither URB597 (0.33 mg/kg i.p.) nor URB937 (0.17 mg/kg i.p.) altered colonic transit time alone or in combination with morphine. (B) The highest dose of morphine (10 mg/kg i.p.) reduced overall fecal boli output, whereas URB597 and URB937 failed to do so when administered alone or in combination with morphine. Data are expressed as the mean \pm S.E.M. $\left(n=5-9\right.$ per group). ${ }^{*} P<0.05$ vs. all groups, one-way ANOVA followed by Tukey's post hoc test; ${ }^{+} P<0.05$ vs. vehicle, one-tailed $t$ test.

(0.17 $\mathrm{mg} / \mathrm{kg}$ i.p.) reduced weight (in milligrams) of fecal boli produced $(P>0.05)$. Neither the synergistic dose of morphine (3.34 $\mathrm{mg} / \mathrm{kg}$ i.p.) $(P>0.05)$ nor the combination of morphine with either URB597 $(P>0.05)$ or URB937 $(P>0.05)$ reduced the weight of fecal boli produced relative to vehicle.

\section{Discussion}

Cannabinoids produce opioid-sparing effects in preclinical studies (Nielsen et al., 2017). Clinically, cannabinoids enhance opioid agonist-induced suppression of the unpleasantness of pain and reduce overall pain scores (Roberts et al., 2006; Abrams et al., 2011). Coadministration of cannabis with oxycodone increased both analgesia and abuse-related subjective effects of oxycodone in humans (Cooper et al., 2018). A recent meta-analysis suggested additional clinical studies with appropriate controls are needed to evaluate opioidsparing effects of cannabinoids in people (Nielsen et al., 2017). In primates, $\Delta^{9}$-tetrahydrocannabinol enhances morphine antinociceptive efficacy and tolerance but does not enhance morphine withdrawal (Gerak and France, 2016). FAAH inhibitors do not produce robust reinforcing effects in primates (Justinova et al., 2008, 2015) consistent with limited abuse liability. Thus, FAAH inhibitors may enhance opioid analgesic efficacy without potentiating abuse-related subjective effects of opioids. To our knowledge, antinociceptive efficacy of FAAH inhibitors has not been evaluated in primates. However, both MGL and FAAH inhibitors enhance morphine's antiallodynic effects in a mouse model of neuropathic pain (Wilkerson et al., 2016, 2017). The present study demonstrated that both brain-permeant and -impermeant inhibitors of FAAH reduce paclitaxel-induced neuropathic pain by engaging cannabinoid receptor mechanisms that are partially overlapping but distinct. Moreover, both the
CNS-penetrant and the peripherally-restricted FAAH inhibitors produced synergistic antiallodynic effects with the opioid analgesic morphine.

Marble burying (Wilkerson et al., 2018), wheel running (Sheahan et al., 2017), and nestlet shredding (Negus et al., 2015) have been postulated to assess pain-depressed behaviors. Therefore, we examined the impact of paclitaxel on marble-burying and nestlet-shredding behaviors. We did not find any effect of paclitaxel on either nestlet-shredding or marble-burying behaviors, consistent with previous reports evaluating nestlet shredding in a different paclitaxel dosing paradigm (Toma et al., 2017). Therefore, we focused the results of our combination studies on measures of evoked pain.

This is the first report comparing efficacy of brain-permeant and -impermeant inhibitors of FAAH in the paclitaxel model of painful peripheral neuropathy. FAAH inhibition reduces inflammatory (Jayamanne et al., 2006; Ahn et al., 2011), neuropathic (Kinsey et al., 2010; Ahn et al., 2011), and visceral (Sakin et al., 2015) pain in animal models. Inhibition of FAAH reduces cisplatin-induced neuropathic nociception in rats (Khasabova et al., 2012; Guindon et al., 2013). However, both brain-permeant and -impermeant FAAH inhibitors produce antiallodynic efficacy in cisplatin-treated rats that can be blocked by either $\mathrm{CB}_{1}$ or $\mathrm{CB}_{2}$ antagonists (Guindon et al., 2013). Both brain-permeant and -impermeant inhibitors of FAAH show similar efficacy, albeit different potencies, in suppressing paclitaxel-induced neuropathic pain, consistent with other reports in different pain models (Clapper et al., 2010; Miller et al., 2012; Sasso et al., 2012; Guindon et al., 2013). Our data demonstrate that inhibition of FAAH outside the CNS is sufficient to reduce paclitaxel-induced neuropathic pain and is solely dependent upon activation of peripheral $\mathrm{CB}_{1}$ receptors. In line with previous reports, the antiallodynic 
efficacy of URB937 was $\mathrm{CB}_{1}$ mediated (Clapper et al., 2010), whereas that of URB597 was dependent on both $\mathrm{CB}_{1}$ and $\mathrm{CB}_{2}$ receptor activation (Jayamanne et al., 2006; Jhaveri et al., 2006; Desroches et al., 2008, 2014; Naidu et al., 2010).

The present study is the first to evaluate the role of peripheral $C_{1}$ receptors in ongoing antiallodynia using the peripherally-restricted $\mathrm{CB}_{1}$ antagonist AM6545. AM6545 fully reversed antiallodynic efficacy of URB937 and partially reversed the antiallodynic efficacy of URB597. Thus, both central and peripheral mechanisms contribute to the antiallodynic efficacy of URB597, and CNS-penetrant and peripherallyrestricted FAAH inhibitors act through distinct mechanisms. FAAH inhibition may also elicit effects independent of cannabinoid receptors that are mediated by peroxisome proliferator-activated receptor $\alpha$ (Hasanein et al., 2008; Sagar et al., 2008), TRPV1 (Guindon et al., 2013; Starowicz et al., 2013), and the $\mu$-opioid receptor (Jhaveri et al., 2006; Haller et al., 2008), among others. Both AM6545 and AM251 fully reversed the antiallodynic effects of URB937, whereas AM630 failed to do so. Our studies suggest the utility of evaluating reversal by AM6545 for discerning the contribution of peripheral versus central antinociceptive mechanisms to ongoing antiallodynic efficacy of analgesic treatments.

In our study, both brain-permeant and -impermeant inhibitors of FAAH produced antinociceptive synergism with morphine. FAAH inhibition has been suggested to produce additive, but not necessarily synergistic, antinociceptive effects in mouse models of neuropathic pain induced by chronic constriction injury (Wilkerson et al., 2017) and visceral pain induced by intraperitoneal injection of acetic acid (Miller et al., 2012). By contrast, palmitoylethanolamide, which produces peroxisome proliferator-activated receptor $\alpha$-mediated antinociception independent of cannabinoid receptors, is increased by FAAH inhibition and produces antinociceptive synergism following coadministration with the opioid tramadol in the formalin test (Déciga-Campos et al., 2015). Rodent models of neuropathic pain may differentially alter cannabinoid and $\mu$-opioid receptor distribution (Stevens et al., 1991; Mitrirattanakul et al., 2006; Bushlin et al., 2010) as well as endocannabinoid tone (Khasabova et al., 2012; Guindon et al., 2013). Differences in endocannabinoid mobilization and/or cannabinoid or opioid receptor densities or efficacies following paclitaxel treatment could account for differences between pain models. We previously reported increases in mRNA for the chemokine MCP1 but no change in $\mathrm{CB}_{1}$ or $\mathrm{CB}_{2}$ mRNA in the lumbar spinal cord of paclitaxeltreated rodents during the maintenance phase of neuropathic pain (Rahn et al., 2014; Deng et al., 2015). However, receptor and mRNA levels in other areas in the CNS and periphery have not been investigated. More work is necessary to characterize the impact of paclitaxel on the density and distributions of $\mathrm{CB}_{1}, \mathrm{CB}_{2}$, and $\mu$-opioid receptors in this model. Interestingly, unilateral dorsal rhizotomy eliminates the vast majority of $\mu$-opioid receptors in the lumbar spinal cord, whereas a substantial population of $\mathrm{CB}_{1}$ receptors, measured in adjacent sections, remain (Hohmann et al., 1999). These observations suggest that the neural substrates that contain $\mathrm{CB}_{1}$ and $\mu$-opioid receptors are not redundant and could provide a neuroanatomical basis for the antinociceptive synergism observed here. Moreover, both cannabinoid and $\mu$-opioid receptors are present in the periphery, where they have been localized to peripheral terminals of primary afferents and peripheral paw tissue (Richardson et al., 1998; Schmidt et al., 2012) and peripheral nerve fibers and endings (Hohmann and Herkenham, 1999a,b). Intraperitoneal injection of $\mathrm{CB}_{1}$ and $\mu$-opioid agonists is also antihyperalgesic (Kolesnikov et al., 1996; Fox et al., 2001; Nackley et al., 2003; Obara et al., 2004; Agarwal et al., 2007). The $\mathrm{CB}_{2}$ agonist AM1241 has been suggested to release the endogenous opioid $\beta$-endorphin in peripheral paw tissue (Ibrahim et al., 2005). However, AM1241 did not elicit a $\mu$-opioid receptor-dependent antinociceptive effect in naïve rats evaluated for mechanical or thermal responsiveness (Rahn et al., 2010). Bioactive lipid mediators generated by URB597 could produce $\mathrm{CB}_{2}$ mediated antiallodynic effects that contribute to URB597based synergy observed with morphine. $\mathrm{CB}_{1}$ and $\mu$-opioid receptors have also been reported to heterodimerize (Hojo et al., 2008), but the extent to which heterodimerization occurs in vivo and contributes to antinociceptive synergism remains unknown.

Both brain-permeant and -impermeant inhibitors of FAAH produced leftward shifts in the dose-response curve of morphine in reducing both paclitaxel-induced mechanical and cold allodynia, consistent with our findings of antinociceptive synergism. The adjunctive therapy reduced the dose of either compound needed to elicit an antiallodynic effect. Importantly, synergistic doses of either FAAH inhibitor did not enhance morphine-induced suppression of colonic motility or morphine-induced reductions in fecal boli number. This is in line with recent findings reporting that both $\mathrm{CB}_{1}$ and $\mathrm{CB}_{2}$ receptor agonists enhance morphine's therapeutic efficacy in reducing neuropathic pain (Wilkerson et al., 2016; Grenald et al., 2017). Due to the large side effect profile of typical orthosteric $\mathrm{CB}_{1}$ agonists, combining opioid-based therapies with inhibitors of FAAH may offer a superior therapeutic strategy with limited unwanted side effects and a morefavorable therapeutic ratio compared with combinations with orthosteric cannabinoid agonists, such as $\Delta^{9}$-tetrahydrocannabinol (Deng et al., 2015). Because URB597 was not selfadministered in primates (Justinova et al., 2008), we also postulate that it would be unlikely to enhance the rewarding effects of morphine.

Coadministration of $\Delta^{9}$-tetrahydrocannabinol and URB597 attenuates morphine tolerance in the tail-flick assay (Hasanein and Ghafari-Vahed, 2016; Zhang et al., 2016). Similarly, a subthreshold dose of an MGL inhibitor with morphine sustains elevated antinociceptive effects that are greater than those produced by either compound delivered alone (Wilkerson et al., 2016). Coadministration of a $\mathrm{CB}_{2}$ agonist prevents morphine tolerance in the tail-flick test in tumorbearing rats (Zhang et al., 2016), and a $\mathrm{CB}_{2}$ agonist was recently shown to prevent morphine tolerance in reducing paclitaxel-induced neuropathic pain (Lin et al., 2018) potentially through alterations of endogenous tone of either system or changes in receptor expression (Cichewicz et al., 2001; Bushlin et al., 2010; Befort, 2015). Our findings suggest that both brain-permeant and -impermeant inhibitors of FAAH reduce paclitaxel-induced neuropathic pain and produce antinociceptive synergism with morphine without exacerbating morphine-induced slowing of colonic transit. In conclusion, FAAH inhibitors produce opioid-sparing properties and may be clinically viable as a safe and effective adjunctive strategy, potentially reducing unwanted side effects of opioids through safer dosing regimens. 


\section{Acknowledgments}

We thank Ana Thomaz for providing design insight on the nestletshredding and marble-burying experiments.

\section{Authorship Contributions}

Participated in research design: Slivicki, Hohmann.

Conducted experiments: Slivicki, Saberi, Iyer.

Contributed new reagents or analytic tools: Vemuri, Makriyannis.

Performed data analysis: Slivicki, Saberi.

Wrote or contributed to the writing of the manuscript: Slivicki, Saberi, Hohmann

\section{References}

Abrams DI, Couey P, Shade SB, Kelly ME, and Benowitz NL (2011) Cannabinoidopioid interaction in chronic pain. Clin Pharmacol Ther 90:844-851.

Agarwal N, Pacher P, Tegeder I, Amaya F, Constantin CE, Brenner GJ, Rubino T, Michalski CW, Marsicano G, Monory K, et al. (2007) Cannabinoids mediate analgesia largely via peripheral type 1 cannabinoid receptors in nociceptors. Nat Neurosci 10:870-879.

Ahn K, Smith SE, Liimatta MB, Beidler D, Sadagopan N, Dudley DT, Young T, Wren P, Zhang Y, Swaney S, et al. (2011) Mechanistic and pharmacological characterization of PF-04457845: a highly potent and selective fatty acid amide hydrolase inhibitor that reduces inflammatory and noninflammatory pain. J Pharmacol Exp Ther 338:114-124

Angoa-Pérez M, Kane MJ, Briggs DI, Francescutti DM, and Kuhn DM (2013) Marble burying and nestlet shredding as tests of repetitive, compulsive-like behaviors in mice. J Vis Exp:50978.

Befort K (2015) Interactions of the opioid and cannabinoid systems in reward: insights from knockout studies. Front Pharmacol 6:6.

Bradford D, Stirling A, Ernault E, Liosatos M, Tracy K, Moseley J, Blahunka P, and Smith MD (2017) The MOBILE study-A phase IIa enriched enrollment randomized withdrawal trial to assess the analgesic efficacy and safety of ASP8477, a fatty acid amide hydrolase inhibitor, in patients with peripheral neuropathic pain. Pain Med 18:2388-2400.

Bushlin I, Rozenfeld R, and Devi LA (2010) Cannabinoid-opioid interactions during neuropathic pain and analgesia. Curr Opin Pharmacol 10:80-86.

Carey LM, Slivicki RA, Leishman E, Cornett B, Mackie K, Bradshaw H, and Hohmann AG (2016) A pro-nociceptive phenotype unmasked in mice lacking fatty-acid amide hydrolase. Mol Pain 12.

Cata JP, Weng HR, Lee BN, Reuben JM, and Dougherty PM (2006) Clinical and experimental findings in humans and animals with chemotherapy-induced peripheral neuropathy. Minerva Anestesiol 72:151-169.

Cichewicz DL (2004) Synergistic interactions between cannabinoid and opioid analgesics. Life Sci 74:1317-1324.

Cichewicz DL, Haller VL, and Welch SP (2001) Changes in opioid and cannabinoid receptor protein following short-term combination treatment with delta(9)tetrahydrocannabinol and morphine. J Pharmacol Exp Ther 297:121-127.

Cichewicz DL and McCarthy EA (2003) Antinociceptive synergy between delta(9)tetrahydrocannabinol and opioids after oral administration. J Pharmacol Exp Ther 304:1010-1015.

Clapper JR, Moreno-Sanz G, Russo R, Guijarro A, Vacondio F, Duranti A, Tontini A, Sanchini S, Sciolino NR, Spradley JM, et al. (2010) Anandamide suppresses pain initiation through a peripheral endocannabinoid mechanism. Nat Neurosci 13: $1265-1270$

Cooper ZD, Bedi G, Ramesh D, Balter R, Comer SD, and Haney M (2018) Impact of co-administration of oxycodone and smoked cannabis on analgesia and abuse liability. Neuropsychopharmacology 43:2046-2055.

Cox ML, Haller VL, and Welch SP (2007) Synergy between delta9 tetrahydrocannabinol and morphine in the arthritic rat. Eur $J$ Pharmacol 567: 125-130.

Cravatt BF, Giang DK, Mayfield SP, Boger DL, Lerner RA, and Gilula NB (1996) Molecular characterization of an enzyme that degrades neuromodulatory fatty-acid amides. Nature 384:83-87.

Déciga-Campos M, Ramírez-Marín PM, and López-Muñoz FJ (2015) Synergistic antinociceptive interaction between palmitoylethanolamide and tramadol in the mouse formalin test. Eur $J$ Pharmacol 765:68-74.

Deng L, Guindon J, Cornett BL, Makriyannis A, Mackie K, and Hohmann AG (2015) Chronic cannabinoid receptor 2 activation reverses paclitaxel neuropathy without tolerance or cannabinoid receptor 1-dependent withdrawal. Biol Psychiatry 77 475-487.

Deng L, Guindon J, Vemuri VK, Thakur GA, White FA, Makriyannis A, and Hohmann AG (2012) The maintenance of cisplatin- and paclitaxel-induced mechanical and cold allodynia is suppressed by cannabinoid $\mathrm{CB}_{2}$ receptor activation and independent of CXCR4 signaling in models of chemotherapy-induced peripheral neuropathy. Mol Pain 8:71.

Desroches J, Charron S, Bouchard JF, and Beaulieu P (2014) Endocannabinoids decrease neuropathic pain-related behavior in mice through the activation of one or both peripheral $\mathrm{CB}_{1}$ and $\mathrm{CB}_{2}$ receptors. Neuropharmacology 77:441-452.

Desroches J, Guindon J, Lambert C, and Beaulieu P (2008) Modulation of the antinociceptive effects of 2-arachidonoyl glycerol by peripherally administered FAAH and MGL inhibitors in a neuropathic pain model. Br J Pharmacol 155:913-924.

Dinh TP, Freund TF, and Piomelli D (2002) A role for monoglyceride lipase in 2-arachidonoylglycerol inactivation. Chem Phys Lipids 121:149-158.

Fox A, Kesingland A, Gentry C, McNair K, Patel S, Urban L, and James I (2001) The role of central and peripheral cannabinoid1 receptors in the antihyperalgesic activity of cannabinoids in a model of neuropathic pain. Pain 92:91-100.
Gatley SJ, Lan R, Pyatt B, Gifford AN, Volkow ND, and Makriyannis A (1997) Binding of the non-classical cannabinoid CP 55,940, and the diarylpyrazole AM251 to rodent brain cannabinoid receptors. Life Sci 61:PL 191-PL 197.

Gerak LR and France CP (2016) Combined treatment with morphine and $\Delta 9$ tetrahydrocannabinol in rhesus monkeys: antinociceptive tolerance and withdrawal. J Pharmacol Exp Ther 357:357-366.

Grenald SA, Young MA, Wang Y, Ossipov MH, Ibrahim MM, Largent-Milnes TM, and Vanderah TW (2017) Synergistic attenuation of chronic pain using mu opioid and cannabinoid receptor 2 agonists. Neuropharmacology 116:59-70.

Guindon J, Lai Y, Takacs SM, Bradshaw HB, and Hohmann AG (2013) Alterations in endocannabinoid tone following chemotherapy-induced peripheral neuropathy: effects of endocannabinoid deactivation inhibitors targeting fatty-acid amide hydrolase and monoacylglycerol lipase in comparison to reference analgesics following cisplatin treatment. Pharmacol Res 67:94-109.

Haller VL, Stevens DL, and Welch SP (2008) Modulation of opioids via protection of anandamide degradation by fatty acid amide hydrolase. Eur J Pharmacol 600: $50-58$

Hasanein P and Ghafari-Vahed M (2016) Fatty acid amide hydrolase inhibitor URB597 prevented tolerance and cognitive deficits induced by chronic morphine administration in rats. Behav Pharmacol 27:37-43.

Hasanein P, Shahidi S, Komaki A, and Mirazi N (2008) Effects of URB597 as an inhibitor of fatty acid amide hydrolase on modulation of nociception in a rat model of cholestasis. Eur J Pharmacol 591:132-135.

Henry SG, Wilsey BL, Melnikow J, and Iosif AM (2015) Dose escalation during the first year of long-term opioid therapy for chronic pain. Pain Med 16:733-744.

Hohmann AG, Briley EM, and Herkenham M (1999) Pre- and postsynaptic distribution of cannabinoid and mu opioid receptors in rat spinal cord. Brain Res 822:17-25.

Hohmann AG and Herkenham M (1999a) Cannabinoid receptors undergo axonal flow in sensory nerves. Neuroscience 92:1171-1175.

Hohmann AG and Herkenham M (1999b) Localization of central cannabinoid CB1 receptor messenger RNA in neuronal subpopulations of rat dorsal root ganglia: a double-label in situ hybridization study. Neuroscience 90:923-931.

Hojo M, Sudo Y, Ando Y, Minami K, Takada M, Matsubara T, Kanaide M, Taniyama $\mathrm{K}$, Sumikawa K, and Uezono Y (2008) mu-Opioid receptor forms a functional heterodimer with cannabinoid CB1 receptor: electrophysiological and FRET assay analysis. $J$ Pharmacol Sci 108:308-319.

Hosohata Y, Quock RM, Hosohata K, Makriyannis A, Consroe P, Roeske WR, and Yamamura HI (1997) AM630 antagonism of cannabinoid-stimulated [35S]GTP gamma S binding in the mouse brain. Eur J Pharmacol 321:R1-R3.

Huggins JP, Smart TS, Langman S, Taylor L, and Young T (2012) An efficient randomised, placebo-controlled clinical trial with the irreversible fatty acid amide hydrolase- 1 inhibitor PF-04457845, which modulates endocannabinoids but fails to induce effective analgesia in patients with pain due to osteoarthritis of the knee. Pain 153:1837-1846.

Ibrahim MM, Porreca F, Lai J, Albrecht PJ, Rice FL, Khodorova A, Davar G, Makriyannis A, Vanderah TW, Mata HP, et al. (2005) CB2 cannabinoid receptor activation produces antinociception by stimulating peripheral release of endogenous opioids. Proc Natl Acad Sci USA 102:3093-3098.

Jayamanne A, Greenwood R, Mitchell VA, Aslan S, Piomelli D, and Vaughan CW (2006) Actions of the FAAH inhibitor URB597 in neuropathic and inflammatory chronic pain models. Br J Pharmacol 147:281-288.

Jhaveri MD, Richardson D, Kendall DA, Barrett DA, and Chapman V (2006) Analgesic effects of fatty acid amide hydrolase inhibition in a rat model of neuropathic pain. J Neurosci 26:13318-13327.

Justinova Z, Mangieri RA, Bortolato M, Chefer SI, Mukhin AG, Clapper JR, King AR, Redhi GH, Yasar S, Piomelli D, et al. (2008) Fatty acid amide hydrolase inhibition heightens anandamide signaling without producing reinforcing effects in primates. Biol Psychiatry 64:930-937.

Justinova Z, Panlilio LV, Moreno-Sanz G, Redhi GH, Auber A, Secci ME, Mascia P, Bandiera T, Armirotti A, Bertorelli R, et al. (2015) Effects of fatty acid amide hydrolase (FAAH) inhibitors in non-human primate models of nicotine reward and relapse. Neuropsychopharmacology 40:2185-2197.

Khasabova IA, Khasabov S, Paz J, Harding-Rose C, Simone DA, and Seybold VS (2012) Cannabinoid type-1 receptor reduces pain and neurotoxicity produced by chemotherapy. J Neurosci 32:7091-7101.

Kinsey SG, Long JZ, Cravatt BF, and Lichtman AH (2010) Fatty acid amide hydrolase and monoacylglycerol lipase inhibitors produce anti-allodynic effects in mice through distinct cannabinoid receptor mechanisms. $J$ Pain 11: 1420-1428.

Kinsey SG, O'Neal ST, Long JZ, Cravatt BF, and Lichtman AH (2011) Inhibition of endocannabinoid catabolic enzymes elicits anxiolytic-like effects in the marble burying assay. Pharmacol Biochem Behav 98:21-27.

Kolesnikov YA, Jain S, Wilson R, and Pasternak GW (1996) Peripheral morphine analgesia: synergy with central sites and a target of morphine tolerance. J Pharmacol Exp Ther 279:502-506.

Kwilasz AJ, Abdullah RA, Poklis JL, Lichtman AH, and Negus SS (2014) Effects of the fatty acid amide hydrolase inhibitor URB597 on pain-stimulated and paindepressed behavior in rats. Behav Pharmacol 25:119-129.

Lee WH, Xu Z, Ashpole NM, Hudmon A, Kulkarni PM, Thakur GA, Lai YY, and Hohmann AG (2015) Small molecule inhibitors of PSD95-nNOS proteinprotein interactions as novel analgesics. Neuropharmacology 97:464-475.

Li GL, Winter H, Arends R, Jay GW, Le V, Young T, and Huggins JP (2012) Assessment of the pharmacology and tolerability of PF-04457845, an irreversible inhibitor of fatty acid amide hydrolase-1, in healthy subjects. Br J Clin Pharmacol 73:706-716.

Lin X, Dhopeshwarkar AS, Huibregtse M, Mackie K, and Hohmann AG (2018) Slowly signaling $G$ protein-biased $\mathrm{CB}_{2}$ cannabinoid receptor agonist LY2828360 suppresses neuropathic pain with sustained efficacy and attenuates morphine tolerance and dependence. Mol Pharmacol 93:49-62. 
Manchikanti L, Helm S, II, Fellows B, Janata JW, Pampati V, Grider JS, and Boswell MV (2012) Opioid epidemic in the United States. Pain Physician 15(3 Suppl): ES9-ES38

Miller LL, Picker MJ, Umberger MD, Schmidt KT, and Dykstra LA (2012) Effects of alterations in cannabinoid signaling, alone and in combination with morphine, on pain-elicited and pain-suppressed behavior in mice. J Pharmacol Exp Ther 342: 177-187.

Mitrirattanakul S, Ramakul N, Guerrero AV, Matsuka Y, Ono T, Iwase H, Mackie K, Faull KF, and Spigelman I (2006) Site-specific increases in peripheral cannabinoid receptors and their endogenous ligands in a model of neuropathic pain. Pain 126 102-114.

Moreno-Sanz G, Barrera B, Guijarro A, d'Elia I, Otero JA, Alvarez AI, Bandiera T, Merino G, and Piomelli D (2011) The ABC membrane transporter ABCG2 prevents access of FAAH inhibitor URB937 to the central nervous system. Pharmacol Res 64:359-363.

Motulsky H (2013) Intuitive Biostatistics: A Nonmathematical Guide to Statistical Thinking, Oxford University Press, New York.

Nackley AG, Suplita RL, II, and Hohmann AG (2003) A peripheral cannabinoid mechanism suppresses spinal fos protein expression and pain behavior in a rat model of inflammation. Neuroscience 117:659-670.

Naidu PS, Kinsey SG, Guo TL, Cravatt BF, and Lichtman AH (2010) Regulation of inflammatory pain by inhibition of fatty acid amide hydrolase. J Pharmacol Exp Ther 334:182-190.

Negus SS, Neddenriep B, Altarifi AA, Carroll FI, Leitl MD, and Miller LL (2015) Effects of ketoprofen, morphine, and kappa opioids on pain-related depression of nesting in mice. Pain 156:1153-1160.

Nielsen S, Sabioni P, Trigo JM, Ware MA, Betz-Stablein BD, Murnion B, Lintzeris N, Khor KE, Farrell M, Smith A, et al. (2017) Opioid-sparing effect of cannabinoids: a systematic review and meta-analysis. Neuropsychopharmacology 42:1752-1765.

Obara I, Przewlocki R, and Przewlocka B (2004) Local peripheral effects of mu-opioid receptor agonists in neuropathic pain in rats. Neurosci Lett 360:85-89.

Olsen Y, Daumit GL, and Ford DE (2006) Opioid prescriptions by U.S. primary care physicians from 1992 to 2001. J Pain 7:225-235.

Paulozzi LJ (2012) Prescription drug overdoses: a review. J Safety Res 43:283-289.

Polomano RC, Mannes AJ, Clark US, and Bennett GJ (2001) A painful peripheral neuropathy in the rat produced by the chemotherapeutic drug, paclitaxel. Pain 94: 293-304.

Raffa RB, Mathiasen JR, and Jacoby HI (1987) Colonic bead expulsion time in normal and mu-opioid receptor deficient (CXBK) mice following central (ICV) administration of mu- and delta-opioid agonists. Life Sci 41:2229-2234.

Rahn EJ, Deng L, Thakur GA, Vemuri K, Zvonok AM, Lai YY, Makriyannis A and Hohmann AG (2014) Prophylactic cannabinoid administration blocks the development of paclitaxel-induced neuropathic nociception during analgesic treatment and following cessation of drug delivery. Mol Pain 10:27.

Rahn EJ and Hohmann AG (2009) Cannabinoids as pharmacotherapies for neuropathic pain: from the bench to the bedside. Neurotherapeutics 6:713-737.

Rahn EJ, Zvonok AM, Makriyannis A, and Hohmann AG (2010) Antinociceptive effects of racemic AM1241 and its chirally synthesized enantiomers: lack of dependence upon opioid receptor activation. AAPS J 12:147-157.

Richardson JD, Kilo S, and Hargreaves KM (1998) Cannabinoids reduce hyperalgesia and inflammation via interaction with peripheral CB1 receptors. Pain 75:111-119.

Roberts JD, Gennings C, and Shih M (2006) Synergistic affective analgesic interaction between delta-9-tetrahydrocannabinol and morphine. Eur J Pharmacol 530:54-58.

Sagar DR, Kendall DA, and Chapman V (2008) Inhibition of fatty acid amide hydrolase produces PPAR-alpha-mediated analgesia in a rat model of inflammatory pain. Br J Pharmacol 155:1297-1306.

Sakin YS, Dogrul A, Ilkaya F, Seyrek M, Ulas UH, Gulsen M, and Bagci S (2015) The effect of FAAH, MAGL, and dual FAAH/MAGL inhibition on inflammatory and colorectal distension-induced visceral pain models in Rodents. Neurogastroenterol Motil 27:936-944.

Sasso O, Bertorelli R, Bandiera T, Scarpelli R, Colombano G, Armirotti A, MorenoSanz G, Reggiani A, and Piomelli D (2012) Peripheral FAAH inhibition causes profound antinociception and protects against indomethacin-induced gastric lesions. Pharmacol Res 65:553-563.

Sasso O, Wagner K, Morisseau C, Inceoglu B, Hammock BD, and Piomelli D (2015) Peripheral FAAH and soluble epoxide hydrolase inhibitors are synergistically antinociceptive. Pharmacol Res 97:7-15.

Schlosburg JE, Blankman JL, Long JZ, Nomura DK, Pan B, Kinsey SG, Nguyen PT, Ramesh D, Booker L, Burston JJ, et al. (2010) Chronic monoacylglycerol lipase blockade causes functional antagonism of the endocannabinoid system. Nat Neurosci 13:1113-1119.

Schmidt Y, Labuz D, Heppenstall PA, and Machelska H (2012) Cutaneous nociceptors lack sensitisation, but reveal $\mu$-opioid receptor-mediated reduction in excitability to mechanical stimulation in neuropathy. Mol Pain 8:81.
Scripture CD, Figg WD, and Sparreboom A (2006) Peripheral neuropathy induced by paclitaxel: recent insights and future perspectives. Curr Neuropharmacol 4: $165-172$.

Sheahan TD, Siuda ER, Bruchas MR, Shepherd AJ, Mohapatra DP, Gereau RW, IV, and Golden JP (2017) Inflammation and nerve injury minimally affect mouse voluntary behaviors proposed as indicators of pain. Neurobiol Pain 2: $1-12$.

Slivicki RA, Ali YO, Lu HC, and Hohmann AG (2016) Impact of genetic reduction of NMNAT2 on chemotherapy-induced losses in cell viability in vitro and periphera neuropathy in vivo. PLoS One 11:e0147620.

Slivicki RA, Xu Z, Kulkarni PM, Pertwee RG, Mackie K, Thakur GA, and Hohmann AG (2017) Positive allosteric modulation of cannabinoid receptor type 1 suppresses pathological pain without producing tolerance or dependence. Biol Psychiatry DOI: 10.1016/j.biopsych.2017.06.032 [published ahead of print]

Smith AE, Slivicki RA, Hohmann AG, and Crystal JD (2017) The chemotherapeutic agent paclitaxel selectively impairs learning while sparing source memory and spatial memory. Behav Brain Res 320:48-57.

Soukupová M, Palazzo E, De Chiaro M, Gatta L, Migliozzi AL, Guida F, Luongo L, Giordano C, Siniscalco D, De Novellis V, et al. (2010) Effects of URB597, an inhibitor of fatty acid amide hydrolase (FAAH), on analgesic activity of paracetamol. Neuroendocrinol Lett 31:507-511.

Starowicz K, Makuch W, Korostynski M, Malek N, Slezak M, Zychowska M, Petrosino S, De Petrocellis L, Cristino L, Przewlocka B, et al. (2013) Full inhibition of spinal FAAH leads to TRPV1-mediated analgesic effects in neuropathic rats and possible lipoxygenase-mediated remodeling of anandamide metabolism. PLoS One 8:e60040.

Stevens CW, Kajander KC, Bennett GJ, and Seybold VS (1991) Bilateral and differential changes in spinal mu, delta and kappa opioid binding in rats with a painful, unilateral neuropathy. Pain 46:315-326.

Tallarida RJ (2006) An overview of drug combination analysis with isobolograms. $J$ Pharmacol Exp Ther 319:1-7.

Tam J, Vemuri VK, Liu J, Bátkai S, Mukhopadhyay B, Godlewski G, Osei-Hyiaman D, Ohnuma S, Ambudkar SV, Pickel J, et al. (2010) Peripheral CB1 cannabinoid receptor blockade improves cardiometabolic risk in mouse models of obesity. J Clin Invest 120:2953-2966.

Tham SM, Angus JA, Tudor EM, and Wright CE (2005) Synergistic and additive interactions of the cannabinoid agonist CP55,940 with mu opioid receptor and alpha2-adrenoceptor agonists in acute pain models in mice. $\mathrm{Br} J$ Pharmacol 144: 875-884

Toma W, Kyte SL, Bagdas D, Alkhlaif Y, Alsharari SD, Lichtman AH, Chen ZJ, Del Fabbro E, Bigbee JW, Gewirtz DA, et al. (2017) Effects of paclitaxel on the development of neuropathy and affective behaviors in the mouse. Neuropharmacology 117:305-315.

Vargas-Schaffer G (2010) Is the WHO analgesic ladder still valid? Twenty-four years of experience. Can Fam Physician 56:514-517, e202-e205.

Wagenlehner FME, van Till JWO, Houbiers JGA, Martina RV, Cerneus DP, Melis JHJM, Majek A, Vjaters E, Urban M, Ramonas H, et al. (2017) Fatty acid amide hydrolase inhibitor treatment in men with chronic prostatitis/chronic pelvic pain syndrome: an adaptive double-blind, randomized controlled trial. Urology 103 191-197.

Wilkerson JL, Curry ZA, Kinlow PD, Mason BL, Hsu KL, van der Stelt M, Cravatt $\mathrm{BF}$, and Lichtman AH (2018) Evaluation of different drug classes on transient sciatic nerve injury-depressed marble burying in mice. Pain 159:1155-1165

Wilkerson JL, Ghosh S, Mustafa M, Abdullah RA, Niphakis MJ, Cabrera R, Maldonado RL, Cravatt BF, and Lichtman AH (2017) The endocannabinoid hydrolysis inhibitor SA-57: intrinsic antinociceptive effects, augmented morphine-induced antinociception, and attenuated heroin seeking behavior in mice. Neuropharmacology 114:156-167.

Wilkerson JL, Niphakis MJ, Grim TW, Mustafa MA, Abdullah RA, Poklis JL, Dewey WL, Akbarali H, Banks ML, Wise LE, et al. (2016) The selective monoacylglycerol lipase inhibitor MJN110 produces opioid-sparing effects in a mouse neuropathic pain model. J Pharmacol Exp Ther 357:145-156.

Woodhams SG, Chapman V, Finn DP, Hohmann AG, and Neugebauer V (2017) The cannabinoid system and pain. Neuropharmacology 124:105-120.

Zhang M, Wang K, Ma M, Tian S, Wei N, and Wang G (2016) Low-dose cannabinoid type 2 receptor agonist attenuates tolerance to repeated morphine administration via regulating $\mu$-opioid receptor expression in Walker 256 tumor-bearing rats. Anesth Analg 122:1031-1037.

Zimmermann M (1983) Ethical guidelines for investigations of experimental pain in conscious animals. Pain 16:109-110.

Address correspondence to: Andrea G. Hohmann, Department of Psychological and Brain Sciences, Indiana University, 1101 E 10th Street, Bloomington, IN 47405-7007. E-mail: hohmanna@indiana.edu 